\title{
Copulatory Wounding and Traumatic Insemination
}

\author{
Klaus Reinhardt ${ }^{1}$, Nils Anthes ${ }^{1}$, and Rolanda Lange ${ }^{1,2}$ \\ ${ }^{1}$ Animal Evolutionary Ecology, Institute of Evolution and Ecology, University of Tübingen, D-72076 \\ Tübingen, Germany \\ ${ }^{2}$ School of Biological Sciences, Monash University, Clayton 3800, Australia \\ Correspondence: k.reinhardt@uni-tuebingen.de
}

Copulatory wounding (CW) is widespread in the animal kingdom, but likely underreported because of its cryptic nature. We use four case studies (Drosophila flies, Siphopteron slugs, Cimex bugs, and Callosobruchus beetles) to show that CW entails physiological and lifehistory costs, but can evolve into a routine mating strategy that, in some species, involves insemination through the wound. Although interspecific variation in CW is documented, few data exist on intraspecific and none on individual differences. Although defensive mechanisms evolve in the wound recipient, our review also indicates that mating costs in species with CW are slightly higher than in other species. Whether such costs are dose- or frequencydependent, and whether defense occurs as resistance or tolerance, decisively affects the evolutionary outcome. In addition to sexual conflict, CW may also become a model system for reproductive isolation. In this context, we put forward a number of predictions, including (1) occasional $\mathrm{CW}$ is more costly than routine $\mathrm{CW},(2) \mathrm{CW}$ is more costly in between- than within-population matings, and (3) in the presence of CW, selection may favor the transmission of sexually transmitted diseases if they induce resource allocation. Finally, we outline, and briefly discuss, several medical implications of CW in humans.

M ales and females do not have the same fitness optima for all traits (Bateman 1948; Parker 1979; see contributions to this collection), which results in intraspecific, intragenomic sexual conflict (Rice and Chippendale 2001). Sex-limited expression of traits is one way in which the conflict over divergent trait optima can be temporarily resolved. Sex-limited trait expression may, however, result in intraspecific, intergenomic conflict in which traits in one sex can reduce the fitness of the other (Rice and Chippendale 2001). Traits related to mating may be particularly involved in this type of conflict. Whereas gamete transfer requires some degree of cooperation, the interaction between males and females during mating rarely results in perfect harmony. Some extreme cases have been reported in which mating attempts by waterfowl or toad males resulted in the immediate death of their mates (Holland Rice 1998). These cases have remained anecdotes, likely because such male behavior will not result in fitness gains and thus be selected against. In other species, mating routinely involves forceful and

Editors: William R. Rice and Sergey Gavrilets

Additional Perspectives on The Genetics and Biology of Sexual Conflict available at www.cshperspectives.org

Copyright (C) 2015 Cold Spring Harbor Laboratory Press; all rights reserved; doi: 10.1101/cshperspect.a017582

Cite this article as Cold Spring Harb Perspect Biol 2015;7:a017582 
K. Reinhardt et al.

apparently aggressive physical contacts between mating partners. A well-studied system concerns the male clasping devices and behaviors to prevent females from escaping during copulation in water striders (Arnqvist and Rowe 2002a,b). This system also shows female evolution in response to male aggression (Arnqvist and Rowe 2002a,b). Other cases of sexual aggression are known as sexual punishment (Clutton-Brock and Parker 1995) or situation exploitation (Reinhardt et al. 2009b), in which members of one sex exploit circumstances or actively produce signals that reduce the ability of the other sex to defend themselves against mating attempts.

One form of seemingly aggressive mating interaction that has received systematic treatment only very recently (Lange et al. 2013a; Tatarnic et al. 2014) concerns cases in which the mating partner's genital tract is injured during copulation. These cases are defined as copulatory wounding (CW) (Box 1) (Lange et al. 2013a). Although CW may appear as an accidental exception and so easily dismissed as being anecdotal, a recent literature review revealing that CW independently evolved in at least 36 taxa (Fig. 1) (Lange et al. 2013a) instead identifies it as a phylogenetically widespread phenomenon.

CW occurs in various forms and can be differently categorized; here, we use the recently unified terminology and categorization of the different types of CW (Box 1) (Lange et al. 2013a). Before we deal with these technical aspects and definitions and discuss the origin of CW and evolutionary consequences of its costs and benefits, we introduce the topic by means of four illustrative case studies. These were selected among other well-studied animal model systems (reviewed by Lange et al. 2013a; Tatarnic et al. 2014) to represent the great diversity of CW mechanisms, while also providing a relatively advanced state of knowledge about their physiological underpinnings. We conclude by illustrating some of the medical and legal consequences of CW in humans.

\section{BOX 1. DEFINITIONS OF TERMS RELATED TO REPRODUCTION AS USED IN THIS REVIEW}

Copulation: Physical coupling of the sperm donor and recipient and intromission of the sperm donor's copulatory organ into the sperm recipient's body (Alexander et al. 1997).

Copulatory organ: Any device used to transfer or receive sperm, including genitalia, spermatophores, and structures that secondarily acquired the function of sperm transfer or receipt.

Copulatory wounding (CW): An infliction of a wound during copulation involving copulatory organs. The routine occurrence of CW (fixed trait) is classified as traumatic mating (TM).

Genitalia: In males, organs that initially in evolution function to transfer sperm and seminal fluid; in females, these are organs that initially served to accommodate male genitalia and/or receive sperm and seminal fluid.

Insemination: Sperm enter the recipient's body (Alexander et al. 1997).

Inverted copulation: A process by which the sperm recipient uses structures to intrude the body of the sperm donor in order to obtain sperm.

Mating: Generic term for animals interacting to breed; more generic than copulation.

Trauma: An externally inflicted physical wound.

Traumatic insemination (TI): The transfer of sperm through a wound (from Lange et al. 2013).

Traumatic mating (TM): Generic term to describe cases where, routinely, the partner's intraB or extragenital integument is wounded by specialized devices in the direct context of copulation (Lange et al. 2013). TM subsumes TI, TST, and TP.

Traumatic penetration (TP): TM without substances being transferred through the trauma caused (Lange et al. 2013).

Traumatic secretion transfer (TST): TM that includes the transfer of secretions, but not sperm through the trauma (from Lange et al. 2013). 
Copulatory Wounding and Traumatic Insemination
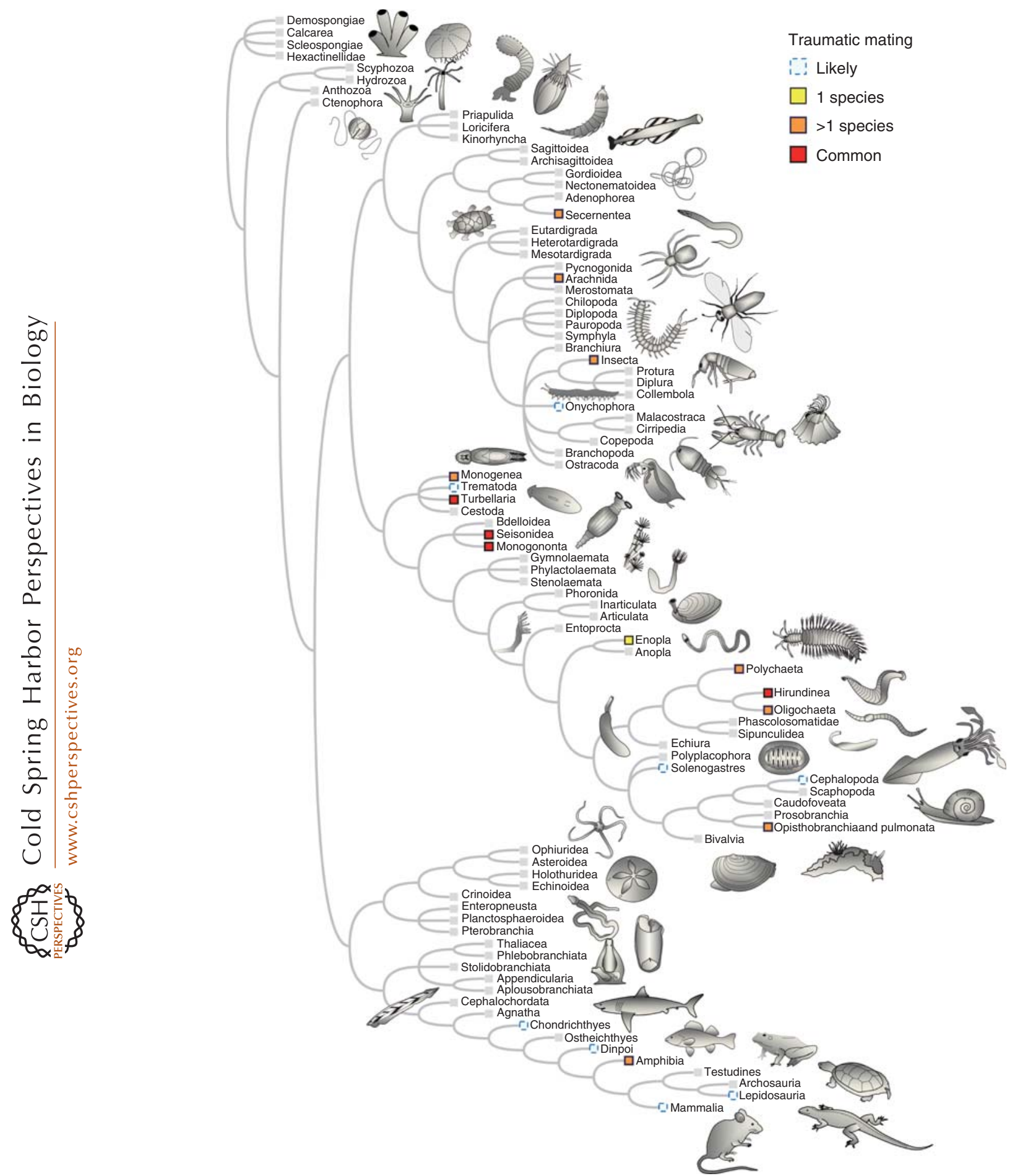

Figure 1. Phylogenetic distribution of TM in the animal kingdom. (Figure modified from Anthes 2010.) 
K. Reinhardt et al.

\section{CASE STUDIES OF CW}

\section{Drosophila: Fruit Flies}

In 2005, CW in Drosophila fruit flies was independently observed by Yoshitaka Kamimura in Hokkaido (Kamimura 2007) and Helen Crudgington in Sheffield (Drosophila subobscura) (H Crudgington, unpubl.). Since then, fruit flies have become one of the best-studied taxa to reveal mechanisms and functions of CW. It occurs regularly and in the female is both intragenital, as well as extragenital (abdomen) (Kamimura 2007, 2010). Wounds are inflicted by appendages of male genitalia (Fig. 2) (Kamimura 2007; Kamimura and Mitsumoto 2011) in at least 23 species of the Drosophila ananassae and melanogaster subgroups, and a few other species (Kamimura 2010).

In the Drosophila melanogaster subgroup, two types of male structures puncture the female abdomen, both ventrally and dorsally (Kamimura and Mitsumoto 2011). The frequency by which copulations result in CW differs among species of this subgroup. In D. melanogaster, Drosophila simulans, and Drosophila teisseri, genital wounding occurred in all observed cases (Kamimura and Mitsumoto 2011, 2012) and represents "traumatic penetration" (TP; Box 1 ), in Drosophila sechellia, CW occurs in 66\% of studied cases (Kamimura 2011).

Seminal fluid is not transferred through the wound in any of the species of the melanogaster group. In contrast, in Drosophila eugracilis, seminal fluid, but not sperm, is transferred through the genital wounds (Kamimura 2010), representing "traumatic secretion transfer" (TST; Box 1).

"Traumatic insemination" (TI; Box 1) has evolved from TP at least twice independently in Drosophila. In addition to the melanogaster group, species of the D. bipectinata species complex in the ananassae subgroup show TI through the genital wounds (Fig. 2) (Kamimura 2007).

The wound-causing genital spines in $D$. ananassae promote anchorage between partners and provide males a benefit in sperm competition (Grieshop and Polak 2012). Costs of this anchorage to females are unknown, but may arise from infection (Kamimura 2012). For instance, the female immune system in $D$. melanogaster responds to seminal fluids (Peng et al. 2005; Domanitskaya et al. 2007), but not to bacteria (Gendrin et al. 2009) introduced to the reproductive tract (Kamimura 2012). However, microbes experimentally deposited on male genital plates persisted for longer and induced stronger immune responses in the male than when deposited on other tissues (Gendrin et al. 2009).

Females in the melanogaster group show a pattern of sclerotized structures that are hypothesized to function as a resistance adaptation (Kamimura and Mitsumoto 2011; Yassin and Orgogozo 2013). Correspondingly, interspecific matings between the sister species Drosophila santomea and Drosophila yakuba resulted in more damaging CW than in intraspecific matings (Kamimura 2012).

\section{Siphopteron: Sea Slugs}

At least five species within the hermaphroditic sea slug genus Siphopteron show CW. All inject prostate fluids into the body of their mate during every mating using a genital appendage terminating in an injection stylet (Fig. 2) (Anthes and Michiels 2007a,b; Lange et al. 2012, 2013b, 2014). Wound infliction and ejaculate transfer through the wound involve different structures (Anthes and Michiels 2007a), providing the potential to isolate the costs of traumatic injections from general mating costs. Whereas high mating rates, in general, cause a decline in female fecundity beyond an intermediate fitness optimum (Lange et al. 2013a), these short-term fecundity costs could not be linked to the wound infliction per se (Lange et al. 2013b), making Siphopteron a candidate to test whether TST is maintained by a paternity benefit to the wound inflictor.

The various Siphopteron species have highly divergent and often species-specific traumatic injection sites (Lange et al. 2014). Siphopteron may, therefore, be a good model to test whether CW occurs localized because of constraints in the mating position or specific wounding sites produce different fitness outcomes. There 

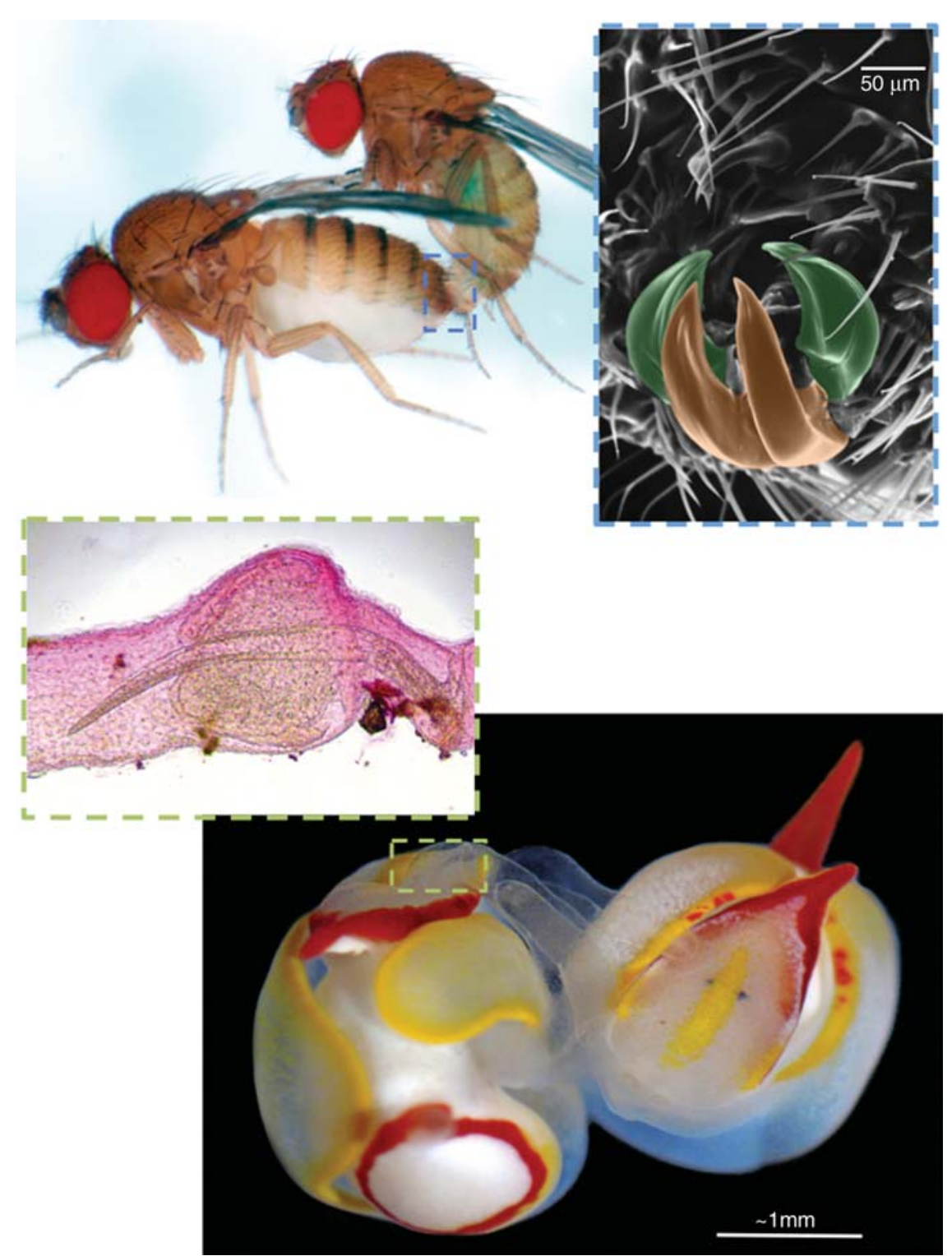

Figure 2. Well-studied model systems of CW. (Top) A mating pair of Drosophila bipectinata, as well as a close-up of a pair of basal processes of the aedeagus (highlighted in orange) and gonopods (highlighted in green) that make a pair of novel, harmful intromittent organs for sperm transfer. (Image from photographer and copyright holder, Y. Kamimura, Keio University, Yokohama, Japan; reprinted, with permission.) (Bottom) A mating pair of Siphopteron species 1 (sensu Lange et al. 2014), showing the position (dashed rectangle) and an enlarged view (inset) of the intromittent organ, a needle-like injection stylet. (Image from photographer and copyright holders, Johanna Werminghausen and Rolanda Lange, University of Tübingen, Germany; reprinted, with permission.) 
K. Reinhardt et al.

is also substantial between- and within-species variation in the shape and length of penile spines and copulatory stylets (Reichel 2011), calling for studies to assess the relationship between variation in genitalia morphology and CW.

\section{Cimicidae: Bedbugs}

Bedbugs (Cimicidae) comprise approximately 100 species, which all show traumatic mating (Usinger 1966) that has been classified as TI (Lange et al. 2013a). Shape variation in male intromittent organs is relatively small between species (Usinger 1966), but length variation has been documented within several species (Usinger 1966; Reinhardt and Jacobs 2006). In the best-studied system, the common bedbug $\mathrm{Ci}$ mex lectularius (Fig. 3), males harbor microbes on their intromittent organs and transfer them to females during mating (Reinhardt et al. 2005; Otti et al. 2013). Females cannot avoid mating by behavioral means (Reinhardt et al. 2009b) and, hence, can neither avoid CW nor infection. Females therefore rely on morphological or physiological defense to ameliorate the costs of CW. In most species, TI occurs localized where a secondary genital structure, the spermalege, has evolved (Fig. 3). In the common bedbug, the spermalege is a complex organ that activates sperm and digests seminal fluid (Davies 1966) and has experimentally been shown to reduce infection (Reinhardt et al. 2003), the effects of wounding (Morrow and Arnqvist 2003), and water loss (Benoit et al. 2012). Despite these defense functions, females do incur costs from an increased mating rate (Stutt and Siva-Jothy 2001; Morrow and Arnqvist 2003; Polanco et al. 2011). When the costs of the trauma and possible infection were kept constant experimentally, higher amounts of ejaculate substances accelerated female mortality, but overall provided benefits to females in the form of higher fecundity and delayed reproductive senescence (Reinhardt et al. 2009a). How precisely female aging is delayed is unknown, but it appears that immuneactive ejaculate substances are involved (Otti et al. 2013).

The various cimicid species differ in the position of where the spermalege is situated on the body. In two species, the spermalege has evolved to having an actual opening that males inseminate into. Following Lange et al. (2013a), these cases are classified as representing TI. However, as is the case in other taxa of true bugs (Carayon 1966a; Tatarnic et al. 2014), mating is, strictly speaking, not traumatic anymore because no wounding is inflicted (see further discussion in the section Major Evolutionary Trends of CW).

Rather peculiarly, males in two cimicid species, Afrocimex constrictus and Latrocimex spectans, wound and inseminate other males (Carayon 1966b; Reinhardt et al. 2007; K Reinhardt and L Holman, unpubl.). Males of at least one of the species, A. constrictus, possess a spermalege, including those structures that have been shown to reduce copulatory infection in C. lectularius (Reinhardt et al. 2007). A certain proportion of females mimic this male-type of spermalege, and these females appear to experience a reduced mating rate (Reinhardt et al. 2007).

\section{Callosobruchus: Bean Weevils}

In several species of the bean weevil genus Callosobruchus, males show TP inflicted by spiny male genitalia (Fig. 3) (Crudgington and SivaJothy 2000; Rönn et al. 2007). Between-species variation is large and the genus has become an outstanding model for testing the functions of traumatic mating and its evolutionary maintenance.

Intraspecific variation in genital spine length exists, and longer genital spines were found to cause more harm to females (Hotzy et al. 2012) and lower female lifetime reproductive success (Rönn and Hotzy 2012). Males benefit from longer genital spines by an increased success in sperm competition (Hotzy and Arnqvist 2009; Hotzy et al. 2012), a success that was, however, not caused by an increased anchorage benefit of longer spines to males (Rönn and Hotzy 2012).

Research in Callosobruchus (Morrow et al. 2003; Edvardsson and Tregenza 2005) has also revealed that the wounding itself of the female is not adaptive for males under sperm competition as hypothesized by allocation theory (Lessels 2006). To the contrary, experimentally wounded 

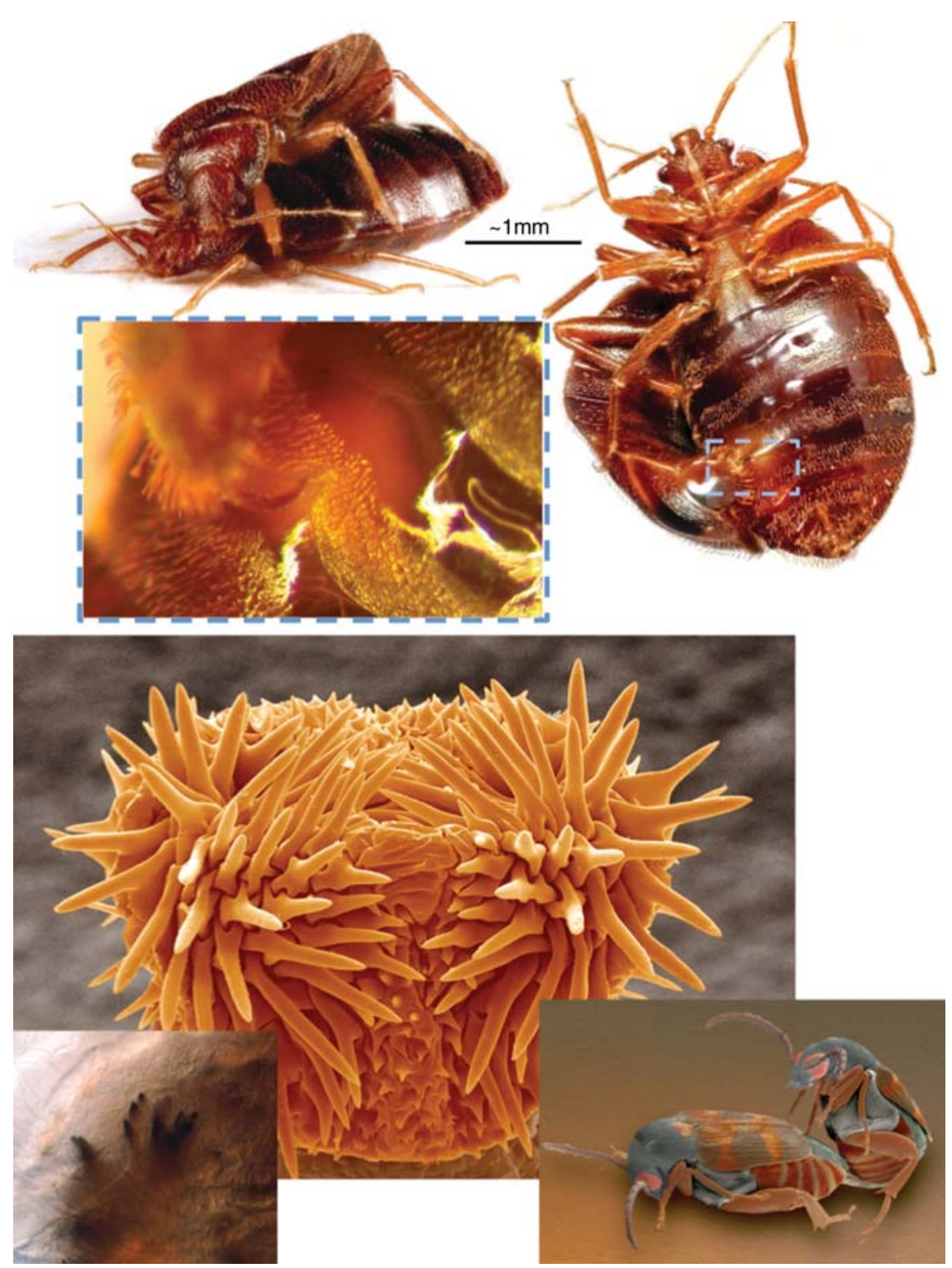

Figure 3. Additional well-studied model systems of CW. (Top) A mating pair of the common bed bug, Cimex lectularius, showing the normal mating position (left), as well as a ventral view of a mating pair. The position of an organ that evolved in response to male harm is indicated by a dashed rectangle. The inset shows the in situ insertion of the male intromittent organ, a hypodermic needle-like structure. (Image from photographer and copyright holder, Richard Naylor, CimexStore, Chepstow, UK; reprinted, with permission.) (Bottom) A mating pair of the seed beetle, Callosobruchus maculatus. The spiny structure is the male penis, which is inserted into the female genital tract regular, causing wounds that are visible as melanized scars (inset). (Image from photographer and copyright holders, PSmicrographs, UK and Mike Siva-Jothy, University of Sheffield, UK; reprinted, with permission.) 
K. Reinhardt et al.

females remated sooner after CWand so promoted sperm competition (Morrow et al. 2003). Recent research further showed that a certain type of female behavior regarded as defensive (Crudgington and Siva-Jothy 2000) may actually carry costs itself and contribute to decreased female lifespan (Wilson and Tomkins 2014).

The following refers to all four previous examples.

With these examples, we have hopefully shown that CW, rather than being an obscure, anecdotal phenomenon, is real, widespread, and important. We will now consider its morphological, physiological, and evolutionary causes and consequences in more detail.

\section{A MECHANICAL ORIGIN OF CW}

CW can occur inside the genital tract of the wound recipient (intragenital wounding) or outside of it (extragenital wounding) (Carayon 1977; Lange et al. 2013a).

\section{Intragenital CW}

Intragenital CW likely derives from a mismatching of male and female genitalia or behavior. For example, reproductive tissue can be ruptured, overstretched, torn, or pierced during copulation if there is a mismatch between male and female reproductive morphology (Fig. 4), but also if behavioral elements in the sequence of copulation are exaggerated or mistimed (Fig. 4). In common bedbugs, Cimex lectularius, for example, in which every copulation is associated with CW (see the section Case Studies), females can make forceful jerking abdomen

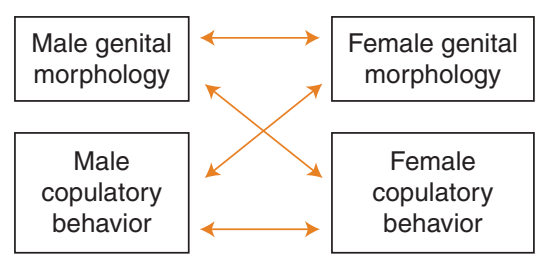

Figure 4. A scheme of mismatches leading to CW. During copulation, any mismatch between male and female genital morphology, or the occurrence of unusual copulatory behavior, can lead to wounding of the partner's, or their own, genital organs. movements to shake off males that attempt to copulate. These sudden movements, however, stop as soon as the male pierces his intromittent organ through the female integument (K Reinhardt, unpubl.). A continuation of these movements during intromission would presumably increase tissue rupture and, thus, be mistimed from the female perspective. Perhaps, such female behavior can explain why, in seed beetles (see the section Case Studies), female behavioral defenses may contribute to decreased female lifespan (Wilson and Tomkins 2014).

Theoretically, when coupled to a fitness benefit to either recipient or inflictor, such accidental, intragenital CW can evolve toward a routine mating strategy involving specialized wounding structures.

It is noteworthy, at this point, that similar mismatch mechanisms underlying copulatory genital injuries have been described in the medical literature using terms such as penovaginal disproportion, excessive force, or unusual behavior at coitus (Eke 2002) (for further discussion, see the section CW in Humans, with a Note on Its Medical and Legal Significance).

\section{Extragenital CW}

Explaining the origin of extragenital $\mathrm{CW}$ is more difficult and probably begins with a deviating male behavioral element, perhaps involving any of the anchorage or harming benefits discussed in Lange et al. (2013a). Before extragenital TI can evolve from accidental extragenital CW, the ability of sperm to survive outside the female sperm receptive organs must also have evolved.

Some species show large variation in the site of extragenital CW, whereas in others CW is strictly localized (Lange et al. 2013a, 2014). It is unclear why specific body sites are being targeted. Although there may be constraints on mating position, it has also been suggested that CW, at specific sites, may increase partner manipulation (Lange et al. 2014), accelerate partner survival (and, hence, increase its reproductive output), or sperm survival.

Not all copulatory mismatches will lead to CW. CW may also be affected by the material 
Copulatory Wounding and Traumatic Insemination

properties of the reproductive tissues involved. For example, elastic female reproductive tissue will accommodate a larger range of male genital morphologies than sclerotized tissue without leading to $\mathrm{CW}$.

\section{WHICH SEX CAUSES CW?}

Because of the different fitness optima for mating traits (Bateman 1948; Parker 1979; references in this collection), males and females experience different selection pressures and it will often be important to identify which sex inflicts the copulatory trauma. Although it is usually males that have specific wounding organs (Lange et al. 2013a), it may be worth pointing out a number of circumstances under which it is difficult to predict which sex inflicts the wound.

1. Consider a male whose copulatory organ does not inflict a genital wound in most female phenotypes, but does so in females that show unusual movement during copulation. Here, the mismatch causing CW arose from a behavioral deviation in the female. The term "wound inflictor" can therefore be ambiguous. In species in which CW is rare, such ambiguity can be circumvented by classifying whether it is the male or female that departs from the sex-specific morphological or behavioral population mean (cf. Fig. 4). However, even this approach is not free from anthropomorphic judgment because it may be the male that induces the behavioral deviation in the female. In species in which CW occurs routinely, the ancestral state of male and female morphology or behavior may be predicted from related species.

The same considerations apply to cases in which the male intromittent organ is injured during copulation. This situation may be self-inflicted, but may also arise from female resistance behavior or morphology and, hence, not be "self"-inflicted.

2. In contrast to self-infliction caused by partner resistance, in several species, the intromittent organs routinely break and the whole or parts thereof remain in the female (nudibranchs: Sekizawa et al. 2013; spiders: Uhl et al. 2010; Izquierdio and Rubio 2011; earwigs: Kamimura 2003; bees: Franck et al. 2002). This self-inflicted CW can acquire adaptive function (such as preventing remating of the partner: Nessler et al. 2007; Uhl et al. 2010), in which case the term "wound inflictor" would, again, be ambiguous, even more so if specific break-off points evolved (e.g., Uhl et al. 2010; Sekizawa et al. 2013) that no longer result in wounding. In other species, injuries to the intromittent organs happen occasionally rather than routinely (moths: Cordero and Miller 2012; humans: the section Case Studies) and their adaptive function, if any, is unknown (but, see Cordero and Miller 2012).

3. Exceptional situations can emerge in hermaphrodites when an individual chews off the male intromittent organ of the mating partner after copulation (as in banana slugs: Leonard et al. 2002). Although such behavior fulfills our definition of CW (Box 1), it does not target the organ that receives the sperm.

In the following, we will use wound inflictor synonymously with male (or the male function in hermaphrodites) and wound recipient synonymously with female (or the female function in hermaphrodites). We do so to facilitate the presentation of our arguments, although it may oversimplify real-world situations, especially in hermaphrodites in which being wounded affects the entire organism of both sexual functions (see Schärer et al. 2014).

Regardless of whether CW is self-inflicted or inflicted by others, the resulting injuries will elicit a similar range of physiological responses.

\section{PHYSIOLOGICAL EFFECTS OF CW}

\section{The Nature of the Physiological Costs}

Once the copulatory trauma is inflicted, one or several immediate effects can occur in the wounded individual: (1) blood loss, (2) the entry of microbes, and (3) the entry of other nonself particles. These effects and subsequent defensive responses have been discussed earlier (Siva-Jothy 2009) and are only briefly considered here. 
K. Reinhardt et al.

\section{Preventing Blood Loss}

The activation of repair cascades, the transport of cells to a wound, and wound closure are ubiquitous among vertebrates and common among invertebrates (Theopold et al. 2004). Although the process of wound healing after CW is almost unstudied, we, here, assume it is similar to general wound healing.

\section{Preventing Microbial Infection}

After CW, external male or female surfacedwelling or sexually transmitted microbes may enter the wound (Eke 2002; Mehta et al. 2009, 2010, 2012; Otti et al. 2009, 2013; Kamimura 2012; and references therein). This elicits a series of responses. For example, in insects, blood clots are formed and prevent systemic infection (Theopold et al. 2004; Haine et al. 2007). After clotting, the next line of defense is the activation of local and systemic immune cascades (Siva-Jothy et al. 2005). It is important to note that genital infections, at least in males, cause systemic responses and sepsis much more often than infection through other tissues (Gendrin et al. 2009).

\section{Responses toward other Non-Self Particles}

Other non-self objects, such as blood and sperm cells, seminal fluid molecules, or particles from the environment, may also elicit clotting or immune responses. Immune responses toward male ejaculate proteins occur widely and seem particularly energy intense (Peng et al. 2005; Domanitskaya et al. 2007; Morrow and Innocenti 2012).

\section{CW Can Elicit Dose- or Frequency- Dependent Costs}

Trauma effects, such as blood loss or ejaculate toxicity, may be dose-dependent such that energy costs increase when more blood is lost or when more seminal protein delivered. Other effects will be frequency-dependent. For example, infection may occur after one CW event regardless of how many microbes have entered. Wound healing and immune responses may also be activated after CW regardless of whether the trauma is a slight rupture, a mucus lesion, or a severe injury. The distinction of dose- and frequency-dependent costs of CW and its important evolutionary consequences (see the section Outlook and Future Research in CW) have not previously been recognized (but see Reinhardt et al. 2011 for a similar argument).

\section{LIFE-HISTORY CONSEQUENCES OF CW}

Physiological studies show that energy is required to reduce, prevent, or outweigh the consequences of trauma. Allocating resources to provide the energy necessary to compensate for blood loss, wound healing, or activation of the immune system is costly (Moret and SchmidHempel 2000). Energy into repair or immune function may be "directly" diverted from other activities, or obtained via increased feeding activity, which "indirectly" takes away resources from other body functions.

Resource allocation will depend on the amount of energy needed and wounded individual's expected lifespan, or more precisely, its residual reproductive value (Clutton-Brock 1984). If CW occurs early in life, more resources may be spent on immune function. If $\mathrm{CW}$ occurs late in life, or is very severe, the wounded individual may invest little into defense and, instead, allocate all remaining resources into maximizing reproductive output in the face of death. This process is known as terminal investment (Clutton-Brock 1984) and has important evolutionary consequences (Johnstone and Keller 2000; Lessels 2006): CW may benefit the wound inflictor by inducing resource allocation to reproduction in the recipient, and so persist evolutionarily. However, empirical studies testing whether CW induces resource allocation are lacking. Although females of three insect species that were injured just after females had mated showed no increased investment (Morrow et al. 2003), the females had been wounded at body sites unconnected to the reproductive tract. Any response in females that occurs specifically in response to CW, rather than normal wounding, would remain undetected. In contrast, infection is known to induce resource allocation (Gustafsson et al. 1994; Adamo 1999; Reaney and Knell 2010). Siva-Jothy (2009) argued that fe- 
Copulatory Wounding and Traumatic Insemination

males are able to predict the time of mating and, therefore, the physiological and infection costs of CW. This predictability may lead to the evolution of $\mathrm{CW}$-anticipating immune responses, the basic mechanism of which has recently been shown for a sexually transmitted disease (STD) (Zhong et al. 2014). Anticipated responses require energy and thus may alter the timing of resource allocation, but will not abolish it.

A speculative, previously unconsidered lifehistory consequence might be that immune responses after CW reduce the costs of later infections-akin to vaccination or immune priming. Because immune priming also occurs in invertebrates (e.g., Little and Kraaijeveld 2004), this mechanism may potentially be widespread. Although this possibility is not further discussed here, it illustrates the complexity of responses to CW (and may be tractable to a solution using mathematical modeling).

\section{EVOLUTIONARY CONSEQUENCES OF CW}

Sexual Conflict and the Evolution of Traumatic Mating

The physiological demands and their life-history consequences induced by $\mathrm{CW}$ will carry fitness costs and affect evolutionary change if $\mathrm{CW}$ varies among wound inflictors and recipients, and if characters affecting CW are heritable (Fig. 5). Similar to the success of any new mutation in a population, the initial occurrence of CW may be beneficial, neutral, or deleterious to either wound inflictor or recipient, and so will persist or disappear. Details of the costs and benefits of CW have extensively been discussed elsewhere (Lange et al. 2013a). Here, we only briefly consider scenarios that occur under sexual conflict, that is, when only one sex, but not the other, incurs fitness costs. This includes a new hypothesis on facilitated transfer of STDs.

\section{Selection for Traumatic Penetration from Accidental CW}

TP can evolve from accidental CW (Fig. 5) if the male fertilizes more eggs after CW because the recipient delays remating or lays more eggs (for details, see Lange et al. 2013a). For the latter possibility, altered resource allocation (see the section Life-History Consequences of CW) (Lessels 2006) is required. D. sechellia may offer a suitable system to study the transition from rare $\mathrm{CW}$ to regular $\mathrm{TP}$. CW, in this species, is

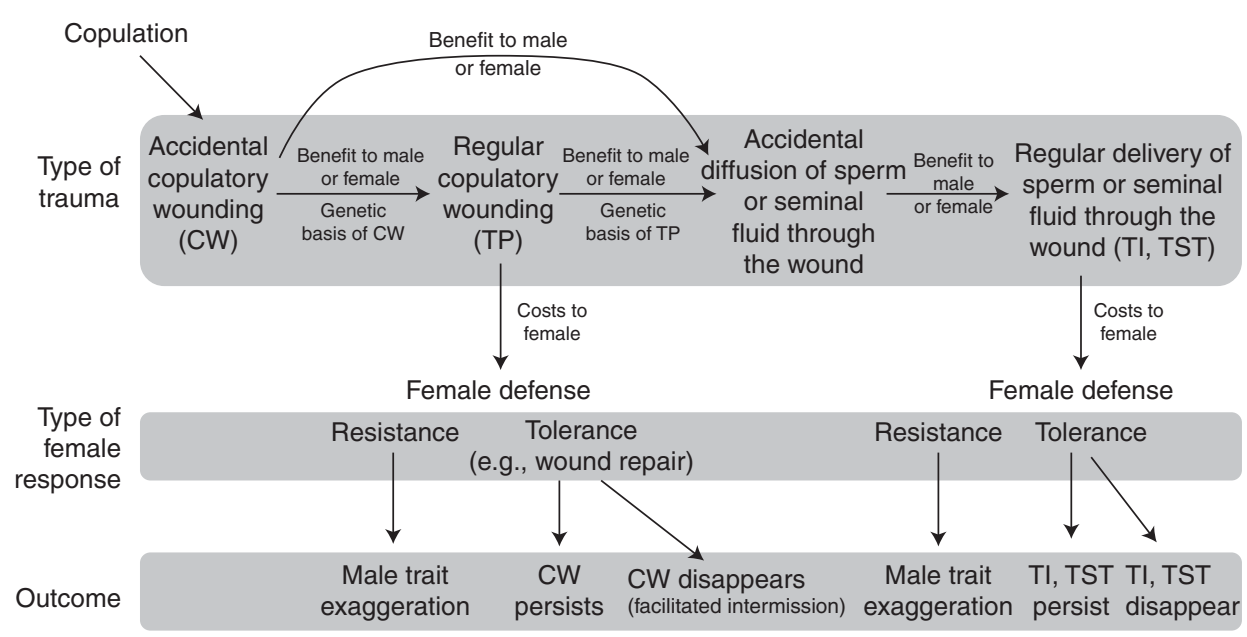

Figure 5. Flow diagram highlighting CW as a signature of sexual conflict. Several outcomes of sexual conflict are possible, including male and female genital exaggeration, male and genital female simplification, and, across populations, male and female genital diversity. The complete disappearance of CW is also possible. As not all genital characters under selection may respond in the same way, CW may also contribute to the evolution of genital complexity. 
K. Reinhardt et al.

facultative and occurs in $66 \%$ of observed cases (Kamimura 2011).

\section{Selection for TI and TST from Accidental Transfer of Sperm and Seminal Fluids}

In several species, sperm or seminal fluids are exclusively transferred traumatically (TI, TST) (Lange et al. 2013a). TI or TST may evolve from accidental deliveries of sperm or seminal fluid if (1) the recipient's short-term reproductive output is increased compared with partners without traumatic delivery, or (2) if the paternity share of the wound inflictor is increased without necessarily increasing the wound recipient's reproductive output (for details, see Lange et al. 2013a). Paternity benefits that are exclusively caused by the traumatic delivery of sperm or seminal fluids are difficult to reveal experimentally, but have been predicted to occur if they bypass the often hostile reproductive tract of the wound recipient, particularly structures that resorb sperm or mix the sperm with that of other males. Such paternity benefits may also arise if the traumatic delivery of seminal fluids manipulates the recipient's physiology and reduces the resorption of currently received sperm.

\section{Selection for the Transfer of STDs in the Wound Inflictor}

If the short-term reproductive rate of the female increases because of resource reallocation (Lessels 2006) and if microbes are involved in eliciting resource allocation (see above), both arguments can be connected to form a novel, testable hypothesis detailed below.

Microbes are found on the intromittent organs of males in several species without necessarily infecting the male (see references in Reinhardt 2010). Such microbes can enter copulatory wounds (see references in Reinhardt et al. 2005; Otti et al. 2009; Siva-Jothy 2009), and elicit immune responses (Otti et al. 2009, 2013; Siva-Jothy 2009). Microbes can also increase an infected host's investment into current reproduction (Gustafsson et al. 1994; Adamo 1999; Reaney and Knell 2010), and sexually transmitted microbes particularly benefit from, and select for, increased mating activity of the host (albeit inducing sterility) (Lockhart et al. 1996). Under the condition that sterility does not occur immediately, copulatory infection, or the associated immune response, may induce the wound recipient to invest more into current reproductive output. This may then lead to selection acting on wound inflictors to harbor microbes on their genitalia or increase microbe transmission to the wound recipient. Under this hypothesis, sexual conflict increases, but aspects of the host-parasite conflict between males (wound inflictors) and their STDs would relax. Experimentally separating the effects of the microbes from the effects of $\mathrm{CW}$ will be challenging.

\section{Defensive Adaptations and Variation in $\mathrm{CW}$}

Wound inflictors and recipients coevolve like other parties in evolutionary conflicts (this collection). This causes costs and benefits of CW, TI, and TST to vary over evolutionary time, and generates several predictions.

\section{Low Costs of CW over Most of Evolutionary Time}

Females will often carry large costs of CW and are expected to adapt very rapidly. As a consequence, the observable costs of CW may be low over much of evolutionary time (longitudinally) and, hence, in many study systems (corresponding to cross-sectional sampling). Therefore, the costs of mating in species with TM may not, generally, be expected to be higher than in species without TM or other forms of CW (Morrow and Arnqvist 2003). This can be tested by comparing female fitness in response to mating rates in species with CW and other species (Table 1, Fig. 6). Following the approach by Arnqvist and Nilsson (2000), we measured the response rate (defined in Table 1) of two fitness proxies to elevated mating rates for both species groups. Response ratios $>1$ indicate benefits, response ratios $<1$ indicate costs.

For female lifespan, the response rate of species with CW (overall 0.89) showed a modest 
Copulatory Wounding and Traumatic Insemination
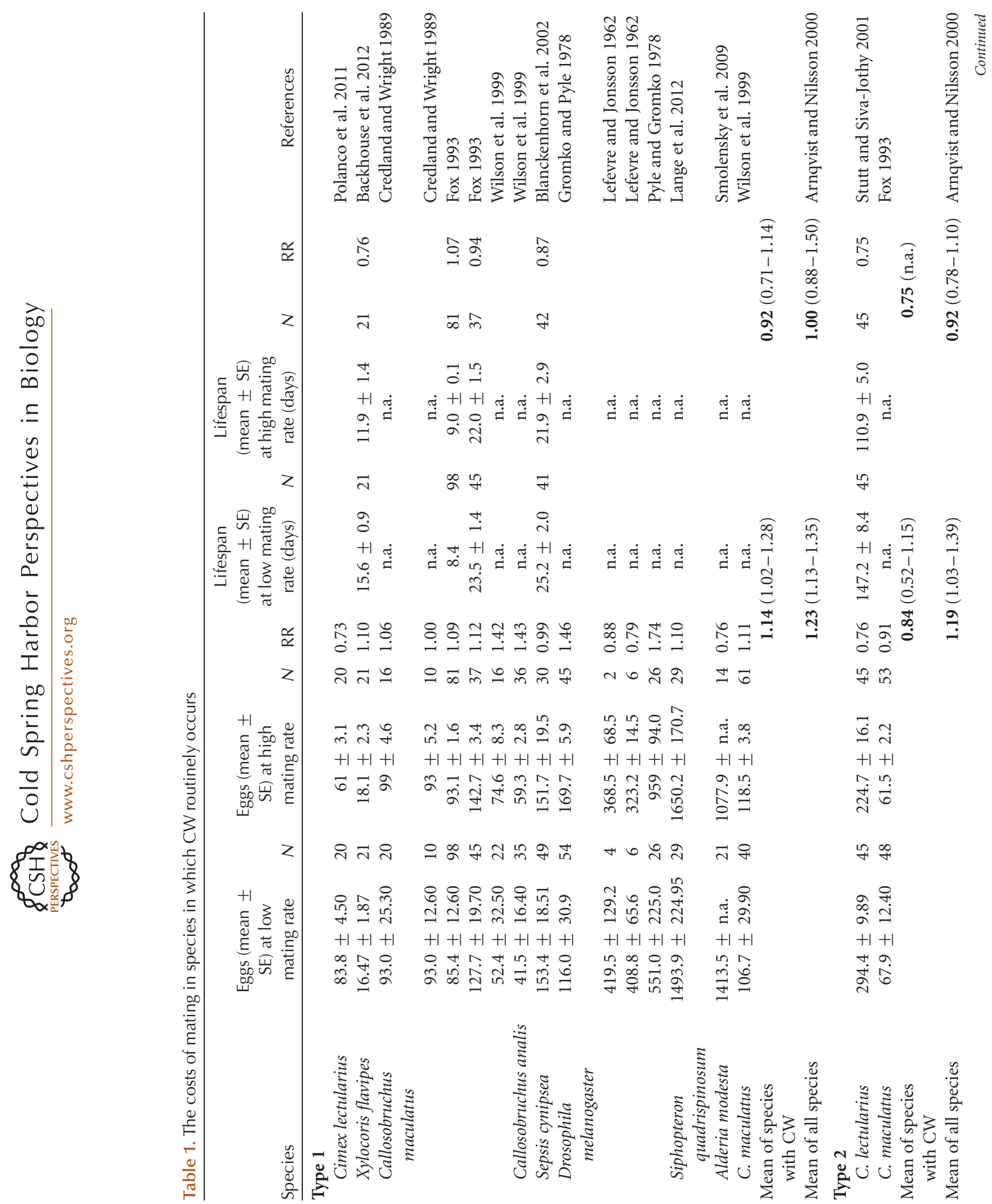
K. Reinhardt et al.
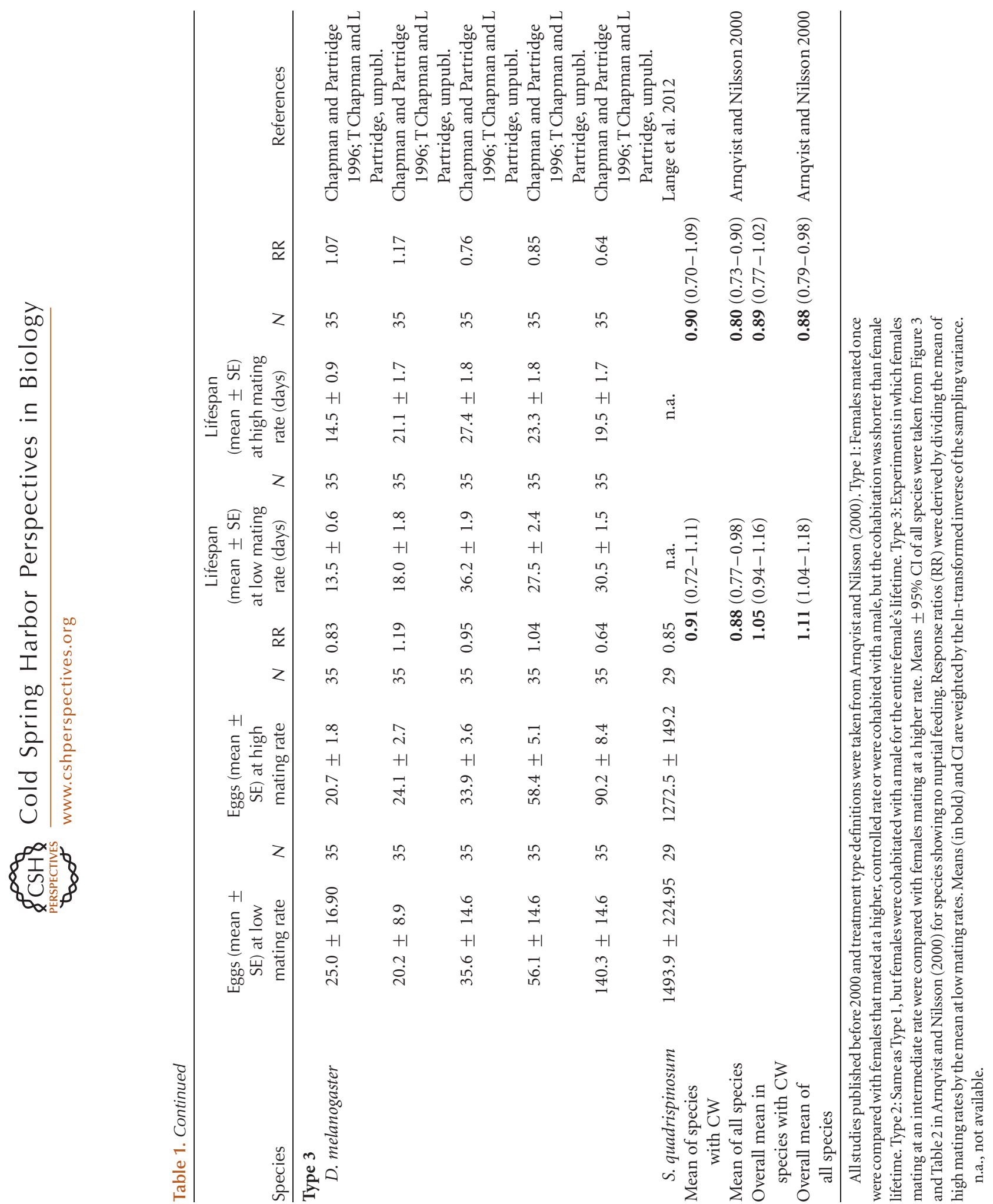


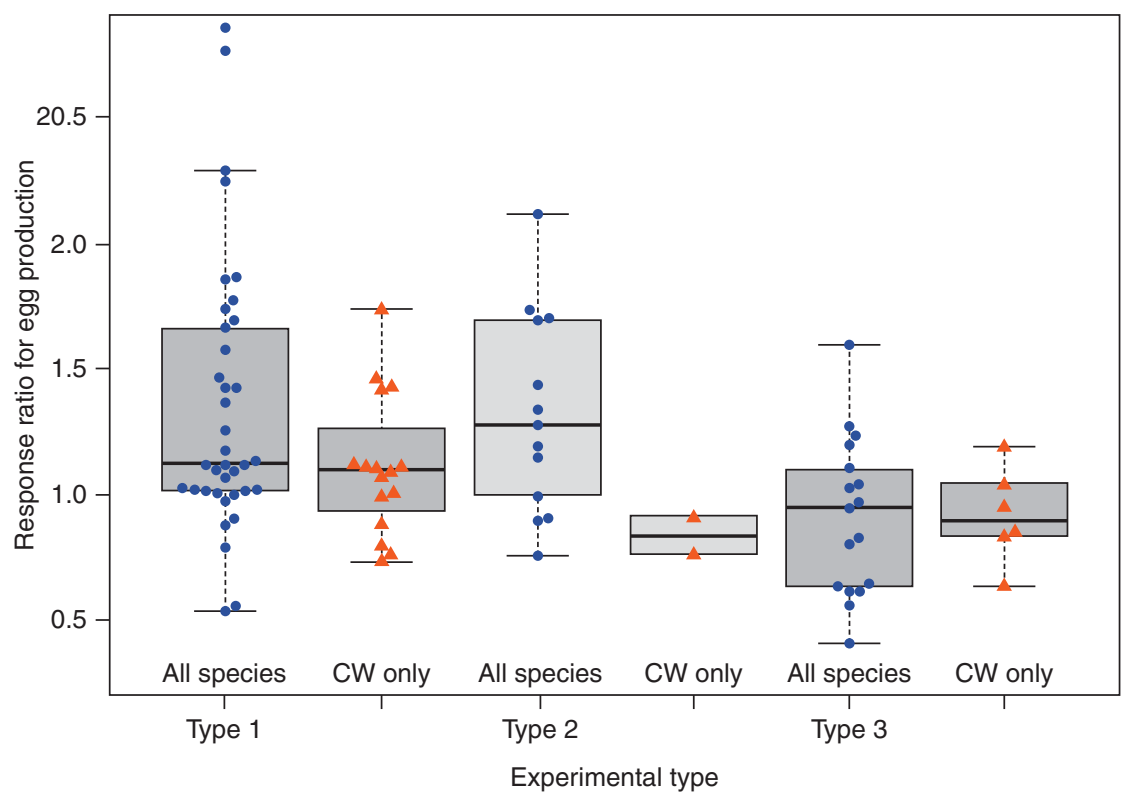

Figure 6. Distribution of response ratios (defined in Table 1) illustrating positive (values $>1$ ) or negative (values $<1)$ effects of enhanced mating frequencies on female egg production. "All species" refers to all species listed by Arnqvist and Nilsson (2000) (blue circles). They are compared with species showing CW ("CW only," orange triangles). Original data for the CW species and definitions of the three experimental types are given in Table 1.

decline in females exposed to high, relative to low, mating rates, and this figure almost perfectly matches the mean response rate of all species (0.88) listed by Arnqvist and Nilsson (2000). Similar to all previously investigated species, species with CW show little variation in response rates among different types of measurement and experimental treatment (Types 1,2 , and 3 as defined in Table 1).

For egg production, a more immediate fitness measure than lifespan, the pattern is a little more differentiated (Fig. 6). The overall response rate in CW species (1.05) tended to be smaller than that reported for all species (1.11) by Arnqvist and Nilsson (2000) (Table 1). This pattern is largely caused by smaller benefits of females exposed to intermediate mating rates compared with low mating rates (Type 1) for CW species (response rate 1.23 vs. 1.14; Fig. 6), as well as the fact that high mating rates or lifelong exposure to males (Type 2) causes costs in females of CW species (0.84), but results in benefits to females of all other species (1.19) (Table 1; Fig. 6). No difference was visible when com- paring intermediate mating rates with high mating rates (Type 3 ).

Taken together, the results indicate that female benefits of multiple mating (response ratios > 1) persist under routine $\mathrm{CW}$, but these benefits are slightly reduced as a consequence of CW. It will be useful to (1) determine in how many of the species listed by Arnqvist and Nilsson (2000) CW occurs cryptically, but has not yet been revealed, and (2) whether this pattern persists once the current bias toward insect studies (Table 1) will be removed (see the section Outlook and Future Research in CW).

\section{Intraspecific Variation in the Incidence of $C W$}

If the costs of CW vary over evolutionary time as outlined above, we predict species to differ also in the rates at which CW is inflicted. However, this prediction cannot currently be tested because none of the few species in which $\mathrm{CW}$ is not fixed (i.e., CW rate $<100 \%$ ) (Table 2 ) have been examined for the costs of CW (cf. Table 1). 
K. Reinhardt et al.

Table 2. Selected examples of inter- and intraspecific variation in CW

\begin{tabular}{|c|c|c|c|}
\hline Group & Species & $\begin{array}{l}\text { Proportion of copulations with } \\
\mathrm{CW} \text { ( N populations examined) }\end{array}$ & References \\
\hline $\begin{array}{l}\text { Earwigs } \\
\quad \text { (Pygidicranidae) }\end{array}$ & $\begin{array}{l}\text { Echinosoma } \\
\text { denticulatum }\end{array}$ & $100 \%(1)$ & Kamimura and Lee 2014 \\
\hline Bedbugs (Cimicidae) & All species & $100 \%$ (all) & Usinger 1966 \\
\hline Damselbugs & Nabis pseudoferus & $3.5 \%(?)$ & Carayon 1966a \\
\hline (Nabidae) & Alleorhynchus furens & $\sim 10 \%$ of males (?) & Carayon 1966a \\
\hline $\begin{array}{l}\text { Spiderweb bugs } \\
\text { (Plokiophilidae) }\end{array}$ & Embiophila species & $7 \%$ of males (?) & Carayon 1966a \\
\hline \multirow[t]{4}{*}{$\begin{array}{l}\text { Fruit flies } \\
\qquad \text { (Drosophila) }\end{array}$} & Drosophila sechellia & $66 \%(1)$ & $\begin{array}{l}\text { Kamimura and } \\
\quad \text { Mitsumoto } 2011\end{array}$ \\
\hline & Drosophila melanogaster & $100 \%(1)$ & Kamimura 2010 \\
\hline & Drosophila simulans & $100 \%(1)$ & $\begin{array}{l}\text { Kamimura and } \\
\text { Mitsumoto } 2011\end{array}$ \\
\hline & Drosophila teisseri & $100 \%(1)$ & $\begin{array}{l}\text { Kamimura and } \\
\text { Mitsumoto } 2012\end{array}$ \\
\hline \multirow{4}{*}{$\begin{array}{l}\text { Ground beetles } \\
\text { (Carabidae) }\end{array}$} & Carabus iwakianus & $0 \%(1)$ & Sota and Kubota 1998 \\
\hline & Carabus maiyasanus & $11 \%(1)$ & Sota and Kubota 1998 \\
\hline & $\begin{array}{l}\text { C. iwakianus male } \times \\
\text { C. maiyasanus } \\
\text { female }\end{array}$ & $30 \%(1)$ & \\
\hline & $\begin{array}{l}\text { C. maiyasanus male } \times \\
\text { C. iwakianus } \\
\text { female }\end{array}$ & $47 \%(1)$ & Sota and Kubota 1998 \\
\hline \multirow[t]{3}{*}{ Moths } & Nystalea aequipars & One of two mated females (1) & Cordero and Miller 2012 \\
\hline & Scotura annulata & One of three mated females (1) & Cordero and Miller 2012 \\
\hline & Malacosoma & One of 68 mated females (1) & Bieman and Witter 1982 \\
\hline \multirow[t]{2}{*}{ Land snails } & Arianta arbustorum & $23 \%-50 \%(3)$ & Baminger et al. 2000 \\
\hline & Cornu aspersum & $73 \%(1)$ & Chase and Vaga 2006 \\
\hline Humans & & $10 \%-52 \%($ several $)$ & $\begin{array}{l}\text { reviewed Astrup et al. } \\
\text { 2012; Lincoln et al. } \\
2013\end{array}$ \\
\hline
\end{tabular}

The proportion of copulations resulting in CW differs across species. The table is based only on examples resulting from systematic anatomical dissections or observations.

The same prediction of variable rates of $\mathrm{CW}$ should hold for populations within a species that evolve independently, but no data exist to test this question. In fact, intraspecific variation in the incidence of CW has only been studied in bedbugs (no variation, 100\%), humans, and dart-shooting snails (Table 2). In dart-shooting snails, Baminger et al. (2000) found that CW is attempted in $23 \%-50 \%$ of individuals. Whether intraspecific variation will evolve into interspecific variation depends on the genetic component of $\mathrm{CW}$, whether $\mathrm{CW}$ is transient in populations or relatively fixed, and how strongly CW acts in reproductive isolation.

If the proportion of CW increases rapidly because wound recipients experiencing low costs are selected for, the costs of CW for individual wound recipients are predicted to be lower in populations in which CW is more common. No data exist that allow testing this prediction. If, in contrast, the proportion of CW is relatively stable, it may be the result of different individuals responding in different ways genetically to CW. This situation may lead 
to female-limited polymorphism or sympatric speciation (Gavrilets and Waxman 2002). Evidence consistent with that model comes from a study of $A$. constrictus, in which some female morphs attracted fewer wounds than others (Reinhardt et al. 2007).

\section{Inter- and Intraindividual Differences}

Intraspecific, interpopulation variation in the proportion of copulations resulting in $\mathrm{CW}$ may be caused by environmental or genetic differences between populations. Consistent genetic differences between populations require that interindividual differences in wounding, or in being wounded, are consistent and are smaller than between-population differences. No data on individual or genotypic differences exist so far. However, Drosophila mutants with genitalia differences (Masly et al. 2011; McNeil et al. 2011; House et al. 2013) may be used to uncover genotypic differences in CW.

\section{CW and Reproductive Isolation \\ CW as a Barrier against Hybridization between Species}

Almost universally, genitalia differ between species. Therefore, in cross-species mating attempts, mismatches between male and female morphology and copulatory behavior (Fig. 4) will be larger in inter- than in intraspecific pairings, and fitness costs will likely be higher. In this case, CW would represent a barrier against hybridization. Empirical examples have confirmed such barrier function. In ground beetles (Sota and Kubota 1998) and Drosophila (Kamimura 2012), interspecific matings resulted in more severe CW than intraspecific mating crosses, but in both cases, asymmetrically in only one direction. Remarkably, the risk of foreign, bacteria-sized particles to invade the copulatory wound was increased in both interspecific pairings (Kamimura 2012). This points toward the possibility that infection, in addition to $\mathrm{CW}$ itself, may generate a hybridization barrier. For traumatically inseminating plant bugs, Tatarnic and Cassis (2013) speculated that the interspe- cific morphological genitalia variation also has evolved by selection against hybridization (character displacement).

\section{$\mathrm{CW}$ as an Isolating Factor in Reproductive Isolation}

CW may not only represent a barrier against hybridization, but also cause reproductive isolation, that is, the emergence of new species. Between-population mismatches in genitalia morphology or copulatory behavior (Fig. 4) may be larger than within-population mismatches. If between-population matings result in more CW and reduced fitness compared with within-population matings, CW will represent an isolating factor (see Rice 1998 for general reasoning). This topic remains unexplored and itself rests on the unexplored assumption that between-individual differences in wounding or being wounded are consistent and have a genetic component.

Consistent interpopulation differences in CW may also drive evolutionary variation in wound healing, but no data exist on healing differences between populations.

\section{Major Evolutionary Trends of CW}

Three major evolutionary trends were identified to be associated with TM (Lange et al. 2013a): (1) increased male and female genital complexity, such as in dart-shooting mollusks (Koene and Schulenburg 2005), (2) convergent evolution to simple, needle-like organs (Eberhard 2006), and (3) thickened or sclerotized tissue at the sites of wounding, such as in bruchid beetles (Rönn et al. 2007) or some bug families (Carayon 1977). We wish to propose a fourth trend that is linked to female tolerance as a defense strategy: (4) the reduction of CW or TM (Fig. 5). In at least one strepsipteran and two bedbug species, as well as in the Lyctocoridae and Plokiophilidae (true bugs), female structures evolved that tolerate, or facilitate, rather than resist male intromission. At body sites in which sister species show copulatory wounds or thickened tissue to resist intromission, females in these groups evolved a novel opening in the 
K. Reinhardt et al.

integument (Usinger 1966; Carayon 1974, 1977; Beani et al. 2005). As a result, sperm delivery is not (any more) associated with trauma. Other families of true bugs contain males with needlelike copulatory organs, as well as females with secondary genital openings (Carayon 1977; Tatarnic and Cassis 2013; Tatarnic et al. 2014). This combination of traits makes it possible, even likely, that these families represent cases in which males initially performed CW, but female tolerance led to CW being lost, although no species exist in which CW currently is observed.

These cases concern the evolution of a secondary genital tract. However, the same arguments may be used to explain the evolution of a primary genital tract. For example, Lange et al. (2013a) highlight that TI occurs in some species within clades of otherwise externally fertilizing polychaete worms. If females in these species would be selected to evolve an opening to receive sperm rather than to experience TI, we would have the scenario that CW actually precedes the evolution of a female genital tract and, hence, copulation in the stricter sense (but, see our broader definition of copulation in Box 1).

\section{CW IN HUMANS, WITH A NOTE ON ITS MEDICAL AND LEGAL SIGNIFICANCE}

Epidemiology of Genital Wounds after Consensual Sexual Intercourse

Wounding of the female, and sometimes the male, genital organs regularly occurs during consensual sexual intercourse in humans. Including only the skin-breaching symptoms that obey our definition of CW (Box 1), such as mucus lesions, abrasions, or lacinations, CW was found in $10 \%-52 \%$ of the examined women (Astrup et al. 2012; Lincoln et al. 2013). However, a standard classification of genital injury after sexual intercourse was not available until recently (Kelly et al. 2013). Variation in CW between studies will therefore include actual variation between populations, but also variation as a result of different methodologies. This uncertainty is likely to also apply to animal studies.
Physiology

In humans, post-CW healing can be inferred from the fact that fewer genital wounds have been found $36 \mathrm{~h}$ after injury than after $0-24 \mathrm{~h}$ (Anderson et al. 2008; Berkowitz 2011; Astrup et al. 2012). The time course of wound healing seems unknown in animal studies, but may be easily considered in arthropods, in which repaired wounds are visible as black melanin scars.

\section{Male Injuries during Consensual Intercourse}

Penile fractures and prepuce lesions can occur during sexual intercourse (Yip et al. 1989; Lee et al. 2000; Szabo and Short 2000; Ozorak et al. 2014). Prepuce lesions are medically significant because they provide a route for systemic STD infections (Szabo and Short 2000; Mehta et al. 2009), and male circumcision during boyhood was associated with fewer injuries in adulthood during sexual intercourse (Mehta et al. 2010). It would be worthwhile to study whether efforts to reduce such STD infections in populations contributed to the cultural emergence of male circumcision.

Penile fractures appear to happen more frequently in stressful situations or when some degree of unusual copulatory behavior is involved (Kramer 2011), suggesting the general mismatch scheme (Fig. 4) does, in principle, also apply to humans.

\section{Nonconsensual Sex, Forced Sex, and Rape}

In cases of rape and nonconsensual sex, injuries to the victim are common (e.g., Riggs et al. 2000). Nonconsensual sex was found to result in much, moderately, or not significantly more female genital injuries compared with consensual sex (Edgardh et al. 1999; Jones et al. 2003; Anderson et al. 2009; Lincoln et al. 2013). However, the lack of a classification scheme of female genital injuries until recently (Kelly et al. 2013) and the occurrence of genital wounds after consensual sex made a recent review conclude that "the presence or absence of genital injury should not be used to render an opinion regard- 
ing consent to sexual intercourse" (Anderson and Sheridan 2012). We do not discuss this topic in more detail as such cases usually represent situations in which human males use sex as a weapon (Geist 1988). Although sperm transfer is involved in a large number of rape cases (e.g., Riggs et al. 2000) we, unlike some investigators, consider such cases as generically, rather than reproductively, aggressive male behavior (see also Coyne 2000; Coyne and Berry 2000). The limited relevance to applying sexual conflict theory is, among others, apparent from the fact that many victims are outside reproductive age (Riggs et al. 2000; Jones et al. 2009).

\section{OUTLOOK AND FUTURE RESEARCH IN CW}

The study of CW has gained momentum, especially in sexual conflict research. Below, we propose that CW is probably still grossly underreported. Getting a more complete picture of the taxonomic distribution and abundance of $\mathrm{CW}$ is an important task for future research. However, we also wish to emphasize that some of the existing data already indicate that the study of CW may provide exceptional contributions to some areas of evolutionary biology.

\section{CW Is Likely Understudied and Underreported}

The 36 cases of CW mentioned by Lange et al. (2013a) may be supplemented by at least six additional examples to include the cases of carabid beetles (Sota and Kubota 1998), two species of notodontid moths (Cordero and Miller 2012), an earwig (Kamimura and Lee 2014), as well as humans (see above), and one more case in fruit flies if CW in D. teisseri (Kamimura and Mitsumoto 2013) represents an independent event. Other recent studies confirmed the occurrence of TM in other taxa (e.g., flower bugs: Shapiro et al. 2010; Tatarnic et al. 2014). We propose that CW will be detected in many more taxa given that CW during consensual sexual intercourse in humans was described only relatively recently. More strikingly, CW was found to occur regularly in D. melanogaster only a few years ago (Ka- mimura 2007), although as one of biology's main model organisms, it had been under anatomical and physiological scrutiny for more than 100 years. There may be at least five additional reasons why $\mathrm{CW}$ is likely more common than currently appreciated:

1. The frequent evolution of copulation, and hence of intromittent organs, from spawning or spermatophore transfer has been shown for various groups, including hermaphrodites (Michiels 1998), insects (Proctor 1998; Heming 2003), and the Bilateria (Mann 1984). Such evolutionary volatility of copulation itself likely goes in hand with substantial variation in genital morphology and copulatory behavior, and so may cause CW by mismatch (Fig. 4).

2. Copulatory organs evolved from a diverse set of developmental structures, representing penises, ectodermal appendages (such as parameres in the insects: Carayon 1966b), mouthparts (such as the pedipalps in spiders: Uhl et al. 2010), and a range of structures collectively known as spermatophores of various origins (Davey 1960; Mann 1984). Such frequent developmental reorganizations may increase the likelihood of copulatory mismatches and, hence, CW.

3. It is a striking pattern that spines on male intromittent organs recurrently evolve. They are found in many taxa, ranging from primates (Stockley 2002), snakes (Zaher 1999), and insects (Rönn et al. 2007; Cordero and Miller 2012) to mollusks (Valdes 2004) or nematodes (Coomans et al. 1988). Some of them are known to cause CW (Lange et al. 2013a), but in most taxa, CW that has not been looked for.

4. In addition to the abundant sources of evolutionary novelties across species, evidence exists for intraspecific variation in genital morphology (Hotzy and Arnqvist 2009) and copulatory behavior in species without currently recognized CW (West-Eberhard 2003; Cordero et al. 2004; Oliveira et al. 2008). This variation may increase opportunities of mismatches (Fig. 4). Particularly 
K. Reinhardt et al.

noteworthy is that intraspecific variation includes variation in male genital spines and other potential wounding devices in CW species (Hotzy and Arnqvist 2009; Cayetano et al. 2011; Masly et al. 2011). Increased potential for $\mathrm{CW}$ arises if variation in genital spines exists also in non-CW species.

5. Finally, not merely one, but several different processes contribute to variation in genital morphology and copulatory behavior, including sexual selection (reviews: Eberhard 1985, 1996; Arnqvist 1998; Hosken and Stockley 2004; experimental evidence: Cayetano et al. 2011; House et al. 2013), environmental variation and natural selection (Reinhardt 2010; experimental evidence: House et al. 2013), phenotypic plasticity (Neufeld and Palmer 2008), and pleiotropy (Müller 1962; Arnqvist and Thornhill 1998; Parzer and Moczek 2008). We suggest that this variety of sources of variation may also contribute to mismatches and CW.

Given the large number of sources of variation, we dare to speculate that no internally fertilizing species with intromittent organs exists in which copulation has not led, at least once, to CW.

Further Need of the Delineation of Costs and Benefits of CW

Throughout this contribution we have, at several places, suggested that sexual conflict and CW research would greatly benefit from quantifying the costs and benefits of CW. We still see this as a primary goal. Although some of the case studies, perhaps, come closest toward achieving this currently, we suggest it may be fruitful to concentrate on species in which CW is not obligatory. Perhaps, we will soon understand how important the rather accidental first step of a mismatch is in the evolution of TM (Fig. 4).

Are the Costs of CW Dose- or FrequencyDependent?

The answer may decisively alter the predicted outcome of evolution. If CW results in frequen- cy-dependent costs, traits affecting the mating rate will be under selection. In contrast, if costs are dose-dependent, genital morphology, physiology, or copulatory behavior will be subject to selection.

\section{Understanding Intraspecific Genital Variation}

If mismatches arise from genital variation (Fig. 4), solving the paradox of the extent and origin of intraspecific genital variation is important. On the one hand, variation between populations is so low that genitalia are routinely used to identify members of the same species or subspecies, even if they are from different populations. This low variation would make mismatches and CW rare. On the other hand, the evolutionary volatility and interspecific variation of copulation and copulatory organs suggests that some source generating genital variation must exist, in which case, CW will be more frequent.

\section{Resistance and Tolerance as Separate Defense Strategies}

Different outcomes of evolutionary conflicts occur depending on whether the offended party responds by resistance or tolerance (Fornoni 2011; Medzhitov et al. 2012). The same seems true for sexual conflict and CW research (see the section Major Evolutionary Trends of CW) (Fig. 5) and we explicitly recommend making this distinction (see also Lessels 2006 for an introduction of palliative traits). Resistance is a defense strategy that causes costs to the offending party and therefore represents a selection pressure that induces coevolution. Tolerance does not impose costs on the offending party and may instead, perhaps more strongly, select (or allow) for evolutionary novelties. As an example, consider the female response to piercing of the vaginal tissue. Females may respond by thickening the connective tissue, which may give males a reduced anchorage and so may reduce their fitness. Alternatively, females may instead accelerate resource allocation to rapid wound healing. Female wound healing does 
Copulatory Wounding and Traumatic Insemination

not impose costs on males (although variation in female healing may cause variation in male fitness) and so may not represent resistance.

\section{CW and Sex-Role Reversal}

A number of species exist in which females possess an intromittent organ and insert it into males (inverted copulations) (Box 1). It would be interesting to study whether CW occurs in these species as well, which include pipefish (Watanabe et al. 2000), planarians (Ullyot and Beauchamp 1931), but also insects (Jolivet 2008). Some of the latter species have normal sex roles and may be useful to separate whether wounding benefits males or the wound inflictor.

\section{CONCLUSION}

We have illustrated that CW is a common phenomenon with implications for the evolution of copulation, sexual conflict, and speciation. Although we have gathered some empirical evidence concerning the evolution, maintenance, and trajectories of CW, many suggestions remain speculative. Largely neglected for more than 100 years, the importance of CW has recently begun to be appreciated. We hope that this review stimulates further research by conceptually and empirically scrutinizing the hypotheses proposed herein, including the more speculative ones on the evolution of TM from accidental CW, the selection for STD transfer, or the proposed mechanisms of interaction in genital variation, behavioral variation, and speciation.

\section{ACKNOWLEDGMENTS}

We thank Ted Morrow, Bill Rice, and an anonymous reviewer for their constructive comments and suggestions, Steffen Roth for information on the Nabidae and, again, Ted Morrow for pointing out, and making available, the paper by Carayon (1966a), which we had overlooked for too long. We thank Yoshitaka Kamimura, Richard Naylor, and Mike Siva-Jothy for providing the images.

\section{REFERENCES}

${ }^{*}$ Reference is also in this collection.

Adamo SA. 1999. Evidence for adaptive changes in egg laying in crickets exposed to bacteria and parasites. Anim Behav 57: 117-124.

Alexander RD, Marshall DC, Cooley JR. 1997. Evolutionary perspectives on insect mating. In Mating systems in insects and arachnids (ed. Choe JC, Crespi BJ), pp. 4-31. Cambridge University Press, Cambridge.

Anderson SL, Sheridan DJ. 2012. Female genital injury following consensual and nonconsensual sex: State of the science. J Emerg Nurs 38: 518-522.

Anderson SL, Parker BJ, Bourguignon CM. 2008. Changes in genital injury patterns over time in women after consensual intercourse. J Forensic Leg Med 15: 306-311.

Anderson SL, Parker BJ, Bourguignon CM. 2009. Predictors of genital injury after nonconsensual intercourse. $A d v$ Emerg Nurs J 31: 236-247.

Anthes N. 2010. Mate choice and reproductive conflict in simultaneous hermaphrodites. In Animal behaviour: Evolution and mechanisms (ed. Kappeler P), pp. 329-357. Springer, Berlin.

Anthes N, Michiels NK. 2007a. Precopulatory stabbing, hypodermic injections and unilateral matings in a hermaphroditic sea slug. Biol Lett 3: 121-124.

Anthes N, Michiels NK. 2007b. Reproductive morphology, mating behaviour, and spawning ecology of cephalaspid sea slugs (Aglajidae and Gastropteridae). Invert Biol 126: 335-365.

Arnqvist G. 1998. Comparative evidence for the evolution of genitalia by sexual selection. Nature 393: 784-786.

Arnqvist G, Nilsson T. 2000. The evolution of polyandry: Multiple mating and female fitness in insects. Anim Behav 60: 145-164.

Arnqvist G, Rowe L. 2002a. Antagonistic coevolution between the sexes in a group of insects. Nature 415: 787789.

Arnqvist G, Rowe L. 2002b. Correlated evolution of male and female morphologies in water striders. Evolution 56: 936-947.

Arnqvist G, Thornhill R. 1998. Evolution of animal genitalia: Patterns of phenotypic and genotypic variation and condition dependence of genital and non-genital morphology in water striders (Heteroptera: Gerridae: Insecta). Genet Res 71: 193-212.

Astrup BS, Ravn P, Lauritsen J, Thomsen JL. 2012. Nature, frequency and duration of genital lesions after consensual sexual intercourse-Implications for legal proceedings. Forensic Sci Int 219: 50-56.

Backhouse A, Sait SM, Cameron TC. 2012. Multiple mating in the traumatically inseminating Warehouse pirate bug, Xylocoris flavipes: Effects on fecundity and longevity. Biol Lett 8: 706-709.

Baminger H, Locher R, Baur B. 2000. Incidence of dart shooting, sperm delivery, and sperm storage in natural populations of the simultaneously hermaphroditic land snail Arianta arbustorum. Can J Zool 78: 1767-1774.

Bateman AJ. 1948. Intra-sexual selection in Drosophila. Heredity 2: $349-368$. 
K. Reinhardt et al.

Beani L, Giusti F, Mercati D, Lupetti P, Paccagnini E, Turillazzi S, Dallai R. 2005. Mating of Xenos vesparum (Rossi) (Strepsiptera, Insecta) revisited. J Morphol 265: 291-303.

Benoit JB, Jajack AJ, Yoder JA. 2012. Multiple traumatic insemination events reduce the ability of bed bug females to maintain water balance. J Comp Physiol B 182: 189198.

Berkowitz CD. 2011. Healing of genital injuries. J Child Sex Abuse 20: 537-547.

Bieman DN, Witter JA. 1982. Mating wounds in Malacosoma: An insight into bed bug mating-behavior. Fla Entomol 65: 377-378.

Blanckenhorn WU, Hosken DJ, Martin OY, Reim C, Teuschl Y, Ward PI. 2002. The costs of copulating in the dung fly Sepsis cynipsea. Behav Ecol 13: 353-358.

Carayon J. 1966a. Traumatic insemination and the paragenital system. In Monograph of Cimicidae (ed. Usinger RL), pp. 81-166. Thomas Say Foundation, Entomological Society of America, College Park, MD.

Carayon J. 1966b. Les inseminations traumatiques accidentelles chez certains Hémiptères Cimicoidea [Accidental traumatic insemination in some Hemiptera Cimicoidea]. CR Acad Sc Paris 262: 2176-2179.

Carayon J. 1974. Étude sur les Hémiptères Plokiophilidae [Study on the Hemiptera Plokiophilidae]. Ann Soc Fr (NS) 10: 499-525.

Carayon J. 1977. Insémination extra-génitale traumatique. In Traite des zoologie-Anatomie, systématique, biologieTome VIII Fascicule V-A-Insectes: Gamétogenèses, fécondation, metamorphoses [Extragenital traumatic insemination. In Textbook of zoology-Anatomy, systematics, biology-Vol VIII Part V-A-Insects: Gametogenesis, fertilization, metamorphoses] (ed. Grassé PP), pp. 351-390. Masson, Paris.

Cayetano L, Maklakov AA, Brooks RC, Bonduriansky R. 2011. Evolution of male and female genitalia following release from sexual selection. Evolution 65: 2171-2183.

Chapman T, Partridge L. 1996. Female fitness in Drosophila melanogaster: An interaction between the effect of nutrition and of encounter rate with males. Proc R Soc B 263 755-759.

Chase R, Vaga K. 2006. Independence, not conflict, characterizes dart-shooting and sperm exchange in a hermaphroditic snail. Behav Ecol Sociobiol 59: 732-739.

Clutton-Brock TH. 1984. Reproductive effort and terminal investment in iteroparous animals. Am Nat 123: 219 229.

Clutton-Brock TH, Parker GA. 1995. Sexual coercion in animal societies. Anim Behav 49: 1345-1365.

Coomans A, Verschuren D, Vanderhaeghen R. 1988. The demanian system, traumatic insemination and reproductive strategy in Oncholaimus oxyuris Ditlevsen (Nematoda, Oncholaimina). Zool Scr 17: 15-23.

Cordero C, Miller JS. 2012. On the evolution and function of caltrop cornuti in Lepidoptera-Potentially damaging male genital structures transferred to females during copulation. J Nat Hist 46: 701-715.

Cordero Rivera A, Andres JA, Cordoba-Aguilar A, Utzeri C. 2004. Postmating sexual selection: Allopatric evolution of sperm competition mechanisms and genital morphology in calopterygid damselflies (Insecta: Odonata). Evolution 58: $349-359$.

Coyne JA. 2000. Of vice and men. The fairy tales of evolutionary psychology. New Republic 3: 27-34.

Coyne JA, Berry A. 2000. Rape as an adaptation. Is this contentious hypothesis advocacy, not science? Nature 404: $121-122$.

Credland PF, Wright AW. 1989. Factors affecting female fecundity in the cowpea seed beetle, Callosobruchus maculatus (Coleoptera: Bruchidae). J Stored Prod Res 25: 125-136.

Crudgington HS, Siva-Jothy MT. 2000. Genital damage, kicking and early death. Nature 407: 855-856.

Davey KG. 1960. The evolution of spermatophores in insects. Proc R Entomol Soc Lond A Gen Entomol 35: 107113.

Davies NT. 1966. Reproductive physiology. In Monograph of Cimicidae (Hemiptera-Heteroptera) (ed. Usinger RL). Thomas Say Foundation, Entomological Society of America, College Park, MD.

Domanitskaya EV, Liu H, Chen S, Kubli E. 2007. The hydroxyproline motif of male sex peptide elicits the innate immune response in Drosophila females. FEBS $J$ 274: $5659-5668$.

Eberhard WG. 1985. Sexual selection and animal genitalia. Harvard University Press, Cambridge, MA.

Eberhard WG. 1996. Female control: Sexual selection by cryptic female choice. Princeton University Press, Princeton, NJ.

Eberhard WG. 2006. Sexually antagonistic coevolution in insects is associated with only limited morphological diversity. J Evol Biol 19: 657-681.

Eberhard WG, Huber BA, Rodriguez RLS, Briceno RD, Salas I, Rodriguez V. 1998. One size fits all? Relationships between the size and degree of variation in genitalia and other body parts in twenty species of insects and spiders. Evolution 52: 415-431.

Edgardh K, von Krogh G, Ormstad K. 1999. Adolescent girls investigated for sexual abuse: History, physical findings and legal outcome. Forensic Sci Int 104: 1-15.

Edvardsson M, Tregenza T. 2005. Why do male Callosobruchus maculatus harm their mates? Behav Ecol 16: 788 793.

Eke N. 2002. Urological complications of coitus. BJU Int 89: 273-277.

Fornoni J. 2011. Ecological and evolutionary implications of plant tolerance to herbivory. Funct Ecol 25: 399-407.

Fox CW. 1993. Multiple mating, lifetime fecundity and female mortality of the bruchid beetle, Callosobruchus maculatus (Coleoptera: Bruchidae). Funct Ecol 7: 203 208.

Franck P, Solignac M, Vautrin D, Cornuet JM, Koeniger G, Koeniger N. 2002. Sperm competition and last-male precedence in the honeybee. Anim Behav 64: 503509.

Gavrilets S, Waxman D. 2002. Sympatric speciation by sexual conflict. Proc Natl Acad Sci 99: 10533-10538.

Geist RF. 1988. Sexually related trauma. Emerg Med Clin North Am 6: 439-466. 
Gendrin M, Welchman DP, Poidevin M, Herve M, Lemaitre B. 2009. Long-range activation of systemic immunity through peptidoglycan diffusion in Drosophila. PLoS Pathog 5: e1000694.

Grieshop K, Polak M. 2012. The precopulatory function of male genital spines in Drosophila ananassae [Doleschall] (Diptera: Drosophilidae) revealed by laser surgery. Evolution 66: 2637-2645.

Gromko MH, Pyle DW. 1978. Sperm competition, male fitness, and repeated mating by female Drosophila melanogaster. Evolution 32: 588-593.

Gustafsson L, Nordling D, Andersson MS, Sheldon BC, Qvarnström A. 1994. Infectious diseases, reproductive effort and the cost of reproduction in birds. Phil Trans $R$ Soc Lond B 346: 323-331.

Haine ER, Rolff J, Siva-Jothy MT. 2007. Functional consequences of blood clotting in insects. Dev Comp Immunol 31: $456-464$.

Heming BS. 2003. Insect development and evolution. Cornell University Press, Ithaca, NY.

Hosken DJ, Stockley P. 2004. Sexual selection and genital evolution. Trends Ecol Evol 19: 87-93.

Hotzy C, Arnqvist G. 2009. Sperm competition favors harmful males in seed beetles. Curr Biol 19: 404-407.

Hotzy C, Polak M, Rönn JL, Arnqvist A. 2012. Phenotypic engineering unveils the function of genital morphology. Curr Biol 22: 2258-2261.

House CM, Simmons LW. 2005. The evolution of male genitalia: Patterns of genetic variation and covariation in the genital sclerites of the dung beetle Onthophagus taurus. J Evol Biol 18: 1281-1292.

House CM, Lewis Z, Hodgson DJ, Wedell N, Sharma MD, Hunt J, Hosken DJ. 2013. Sexual and natural selection both influence male genital evolution. PLOS ONE 8: e63807.

Izquierdo MA, Rubio GD. 2011. Male genital mutilation in the high-mountain goblin spider, Unicorn catleyi. J Insect Sci 11: 118.

Johnstone RA, Keller L. 2000. How males can gain by harming their mates: Sexual conflict, seminal toxins, and the cost of mating. Am Nat 156: 368-377.

Jolivet P. 2008. Inverted copulation. In Encyclopedia of entomology (ed. Capinera JL), pp. 2014-2044. Springer, New York.

Jones JS, Rossman L, Hartman M, Alexander CC. 2003. Anogenital injuries in adolescents after consensual sexual intercourse. Acad Emerg Med 10: 1378-1383.

Jones JS, Rossman L, Diegel R, Van Order P, Wynn BN. 2009. Sexual assault in postmenopausal women: Epidemiology and patterns of genital injury. Am J Emerg Med 27: 922929.

Kamimura Y. 2003. Effects of broken male intromittent organs on the sperm storage capacity of female earwigs, Euborellia plebeja. J Ethol 21: 29-35.

Kamimura Y. 2007. Twin intromittent organs of Drosophila for traumatic insemination. Biol Lett 3: 401-404.

Kamimura Y. 2010. Copulation anatomy of Drosophila melanogaster (Diptera: Drosophilidae): Wound-making organs and their possible roles. Zoomorphology 129: $163-$ 174 .
Kamimura Y. 2012. Correlated evolutionary changes in Drosophila female genitalia reduce the possible infection risk caused by male copulatory wounding. Behav Ecol Sociobiol 66: 1107-1114.

Kamimura Y, Lee C-Y. 2014. Mating and genital coupling in the primitive earwig species Echinosoma denticulatum (Pygidicranidae): Implications for genital evolution in dermapteran phylogeny. Arthrop Syst Phylog 72: 11-21.

Kamimura Y, Mitsumoto H. 2011. Comparative copulation anatomy of the Drosophila melanogaster species complex (Diptera: Drosophilidae). Entomol Sci 14: 399-410.

Kamimura Y, Mitsumoto H. 2012. Genital coupling and copulatory wounding in Drosophila teissieri (Diptera: Drosophilidae). Can J Zool 90: 1437-1440.

Kelly DL, Larkin HJ, Cosby CD, Paolinetti LA. 2013. Derivation of the Genital Injury Severity Scale (GISS): A concise instrument for description and measurement of external female genital injury after sexual intercourse. $J$ Forensic Leg Med 20: 724-731.

Koene JM, Schulenburg H. 2005. Shooting darts: Co-evolution and counter-adaptation in hermaphroditic snails. BMC Evol Biol 5: 25.

Kramer AC. 2011. Penile fracture seems more likely during sex under stressful situations. J Sex Med 8: 3414-3417.

Lange R, Gerlach T, Beninde J, Werminghausen J, Reichel V, Anthes N. 2012. Female fitness optimum at intermediate mating rates under traumatic mating. PLoS ONE 7: e43234.

Lange R, Reinhardt K, Michiels NK, Anthes N. 2013a. Functions, mechanisms, and evolution of traumatic mating. Biol Rev 88: 585-601.

Lange R, Werminghausen J, Anthes A. 2013b. Does traumatic secretion transfer manipulate mating roles or reproductive output in a hermaphroditic sea slug? Behav Ecol Sociobiol 67: 1239-1247.

Lange R, Werminghausen J, Anthes N. 2014. Cephalo-traumatic secretion transfer in a hermaphrodite sea slug. $R$ Soc Lond B 281: 20132424.

Lee J, Singh B, Kravets FG, Trocchia A, Waltzer WC, Khan SA. 2000. Sexually acquired vascular injuries of the penis: A review. J Trauma 49: 351-358.

Lefevre G Jr, Jonsson UB. 1962. Sperm transfer, storage, displacement, and utilization in Drosophila melanogaster. Genetics 47: 1719-1736.

Leonard JL, Pearse JS, Harper AB. 2002. Comparative reproductive biology of Ariolimax californicus and A. dolichophallus (Gastropoda: Stylommatophora). Invert Reprod Dev 41: 83-93.

Lessells CM. 2006. The evolutionary outcome of sexual conflict. Phil Trans R Soc Lond B 361: 301-317.

Lincoln C, Perera R, Jacobs I, Ward A. 2013. Macroscopically detected female genital injury after consensual and nonconsensual vaginal penetration: A prospective comparison study. J Forensic Leg Med 20: 884-901.

Little TJ, Kraaijeveld AR. 2004. Ecological and evolutionary implications of immunological priming in invertebrates. Trends Ecol Evol 19: 58-60.

Lockhart AB, Thrall PH, Antonovics J. 1996 Sexually transmitted diseases in animals: Ecological and evolutionary implications. Biol Rev 71: 415-471. 
K. Reinhardt et al.

Mann T. 1984. Spermatophores: Development, structure, biochemical attributes, and role in the transfer of spermatozoa. Springer, New York.

Masly JP, Dalton JE, Srivastava S, Chen L, Arbeitman MN 2011. The genetic basis of rapidly evolving male genital morphology in Drosophila. Genetics 189: 357-374.

McNeil CL, Bain CL, Macdonald SJ. 2011. Multiple quantitative trait loci influence the shape of a male-specific genital structure in Drosophila melanogaster. G3 (Bethesda) 1: 343-351.

Medzhitov R, Schendier DS, Soares MP. 2012. Disease tolerance as a defense strategy. Science 335: 936-941.

Mehta SD, Moses S, Agot K, Parker CB, Ndinya-Achola JO, Maclean I, Bailey RC. 2009. Adult male circumcision does not reduce risk of incident Neisseria gonorrhoeae, Chlamydia trachomatis, or Trichomonas vaginalis infection: Results from a randomized controlled trial in Kenya. J Infect Dis 200: $370-378$.

Mehta SD, Krieger JN, Agot K, Moses S, Ndinya-Achola JO, Parker C, Bailey RC. 2010. Circumcision and reduced risk of self-reported penile coital injuries: Results from a randomized controlled trial in Kisumu, Kenya. J Urol 184: 203-209.

Mehta SD, Moses S, Parker CB, Agot K, Maclean I, Bailey RC. 2012. Circumcision status and incident herpes simplex virus type 2 infection, genital ulcer disease, and HIV infection. AIDS 26: 1141-1149.

Michiels NK. 1998. Mating conflicts and sperm competition in simultaneous hermaphrodites. In Sperm competition and sexual selection (ed. Birkhead TR, Møller AP), pp. 219-254. Academic, San Diego.

Moret Y, Schmid-Hempel P. 2000. Survival for immunity: The price of immune system activation for bumblebee workers. Science 290: 1166-1168.

Morrow EH, Arnqvist G. 2003. Costly traumatic insemination and a female counter-adaptation in bed bugs. $\operatorname{Proc} R$ Soc Lond B 270: 2377-2381.

Morrow EH, Innocenti P. 2012. Female postmating immune responses, immune system evolution and immunogenic males. Biol Rev 87: 631-638.

Morrow EH, Arnqvist G, Pitnick S. 2003. Adaptation versus pleiotropy: Why do males harm their mates? Behav Ecol 14: $802-806$.

Müller HJ. 1962. Die variabilität der genitalstrukturen bei zikaden und ihre biologische und taxonomische bedeutung [The variability of genitalic structures in planthoppers and its biological and taxonomic significance]. Mittbl Insektenkd 6: 36-42.

Nessler SH, Uhl G, Schneider JM. 2007. Genital damage in the orb-web spider Argiope bruennichi (Araneae: Araneidae) increases paternity success. Behav Ecol 18: 174-181.

Neufeld CJ, Palmer AR. 2008. Precisely proportioned: Intertidal barnacles alter penis form to suit coastal wave action. Proc R Soc Lond B 275: 1081-1087.

Oliveira RF, Taborsky M, Brockmann HJ. 2008. Alternative reproductive tactics: An integrative approach. Cambridge University Press, Cambridge.

Otti O, Naylor R, Siva-Jothy MT, Reinhardt K. 2009. Bacteriolytic activity in the ejaculate of an insect. Am Nat 174: 292-295.
Otti O, McTighe AP, Reinhardt K. 2013. In vitro antimicrobial sperm protection by an ejaculate-like substance. Funct Ecol 27: 219-226.

Özorak A, Hoşcan MB, Oksay T, Güzel A, Koşar A. 2014. Management and outcomes of penile fracture: 10 years' experience from a tertiary care center. Int Urol Nephrol 46: 519-522.

Parker GA. 1979. Sexual selection and sexual conflict. In Sexual selection and reproductive competition in insects (ed. Blum MS, Blum NA), pp. 123-163. Academic, New York.

Parzer HF, Moczek AP. 2008. Rapid antagonistic coevolution between primary and secondary sexual characters in horned beetles. Evolution 62: 2423-2428.

Peng J, Zipperlen P, Kubli E. 2005. Drosophila sex-peptide stimulates female innate immune system after mating via Toll and Imd pathways. Curr Biol 15: 1690-1694.

Polanco A, Miller D, Brewster C. 2011. Reproductive potential of field-collected populations of Cimex lectularius $\mathrm{L}$. and the cost of traumatic insemination. Insects 2: 326335.

Proctor HC. 1998. Indirect sperm transfer in arthropods: Behavioural and evolutionary trends. A Rev Entomol 43: 153-174.

Pyle DW, Gromko MH. 1978. Repeated mating by female Drosophila melanogaster: The adaptive importance. Experientia 34: 449-450.

Reaney LT, Knell RJ. 2010. Immune activation but not male quality affects female current reproductive investment in a dung beetle. Behav Ecol 21: 1367-1372.

Reichel V. 2011. "Penis morphology, mating strategies and fitness effects in simultaneous hermaphrodites." Diploma thesis, Eberhard Karls Universität, Tübingen, Germany, pp. 1-48.

Reinhardt K. 2010. Natural selection and genital variation: A role for the environment, parasites and sperm ageing? Genetica 138: 119-127.

Reinhardt K, Jacobs DS. 2006. Abundance of Cacodmus villosus (Stål, 1855) (Heteroptera: Cimicidae) on its host, Neoromica capensis (Chiroptera: Verspertillionidae). Afr Entomol 14: 398-400.

Reinhardt K, Naylor RA, Siva-Jothy MT. 2003. Reducing a cost of traumatic insemination: Female bed bugs evolve a unique organ. Proc R Soc Lond B 270: 2371-2375.

Reinhardt K, Naylor RA, Siva-Jothy MT. 2005. Potential sexual transmission of environmental microbes in a traumatically inseminating insect. Ecol Entomol 30: 607-611.

Reinhardt K, Harney E, Naylor R, Gorb S, Siva-Jothy MT. 2007. Female-limited polymorphism in the copulatory organ of a traumatically inseminating insect. Am Nat 170: 931-935.

Reinhardt K, Naylor RA, Siva-Jothy MT. 2009a. Ejaculate components delay reproductive senescence while elevating female reproductive rate in an insect. Proc Natl Acad Sci 106: 21743-21747.

Reinhardt K, Naylor RA, Siva-Jothy MT. 2009b. Situation exploitation: Higher male mating success when female resistance is reduced by feeding. Evolution 63: 29-39. 
Reinhardt K, Naylor RA, Siva-Jothy MT. 2011. Male mating rate is constrained by seminal fluid availability in bedbugs, Cimex lectularius. PLoS ONE 6: e22082.

Rice WR. 1998. Speciation by sexual conflict. In Endless forms: Species and speciation (ed. Howard DJ, Berlocher SH), pp. 261-270. Oxford University Press, Oxford.

Rice WR, Chippendale A. 2001. Intersexual ontogenetic conflict. J Evol Biol 14: 685-693.

Riggs N, Houry D, Long G, Markovchick V, Feldhaus KM. 2000. Analysis of 1,076 cases of sexual assault. Ann Emerg Med 35: 358-362.

Rönn JL, Hotzy C. 2012. Do longer genital spines in male seed beetles function as better anchors during mating? Anim Behav 83: 75-79.

Rönn J, Katvala M, Arnqvist G. 2007. Coevolution between harmful male genitalia and female resistance in seed beetles. Proc Natl Acad Sci 104: 10921-10925.

*Schärer L, Janick T, Ramm SA. 2014. Sexual conflict in hermaphrodites. Cold Spring Harb Perspect Biol doi: 10.1101/cshperspect.a017673.

Sekizawa A, Seki S, Tokuzato M, Shiga S, Nakashima Y. 2013. Disposable penis and its replenishment in a simultaneous hermaphrodite. Biol Lett 9: 20121150.

Shapiro JP, Shirk PD, Kelley K., Lewis TM, Horton DR. 2010. Identity of two sympatric species of Orius (Hemiptera: Heteroptera: Anthocoridae). J Insect Sci 10: 189.

Siva-Jothy MT. 2009. Reproductive immunity. In Insect infection and immunity (ed. Rolff J, Reynolds SE), pp. 241250. Oxford University Press, Oxford.

Siva-Jothy MT, Moret Y, Rolff J. 2005. Insect Immunity: An evolutionary ecology perspective. Adv Insect Physiol 32: $1-48$.

Smolensky N, Romero MR, Krug PJ. 2009. Evidence for costs of mating and self-fertilization in a simultaneous hermaphrodite with hypodermic insemination, the Opisthobranch Alderia willowi. Biol Bull 216: 188-199.

Sota T, Kubota K. 1998. Genital lock-and-key as a selective agent against hybridization. Evolution 52: 1507-1513.

Stockley P. 2002. Sperm competition risk and male genital anatomy: Comparative evidence for reduced duration of female sexual receptivity in primates with penile spines. Evol Ecol 16: 123-137.

Stutt AD, Siva-Jothy MT. 2001. Traumatic insemination and sexual conflict in the bed bug Cimex lectularius. Proc Natl Acad Sci 98: 5683-5687.

Szabo R, Short RV. 2000. How does male circumcision protect against HIV infection? Brit Med J 320: $1592-$ 1594.
Tatarnic NJ, Cassis G. 2013. Surviving in sympatry: Paragenital divergence and sexual mimicry between a pair of traumatically inseminating plant bugs. Am Nat 182: $542-551$.

Tatarnic NJ, Cassis G, Siva-Jothy MT. 2014. Traumatic insemination in terrestrial arthropods. A Rev Entomol 59: 245-261.

Theopold U, Schmidt O, Söderhall K, Dushay MS. 2004. Coagulation in arthropods: Defence, wound closure and healing. Trends Immunol 25: 289-294.

Uhl G, Nessler SH, Schneider JM. 2010. Securing paternity in spiders: A review on occurrence and effects of mating plugs and male genital mutilation. Genetica 138: 75-104.

Ullyot P, Beauchamp RSA. 1931. Mechanisms for the prevention of self-fertilization in some species of fresh-water triclads. Q J Microsc Sci 74: 477-490.

Usinger RL. 1966. Monograph of Cimicidae (Hemiptera-Heteroptera), Vol. 7. Thomas Say Foundation, Entomological Society of America, College Park, MD.

Valdes A. 2004. Morphology of the penial hooks and vaginal cuticular lining of some dorid nudibranchs (Mollusca, Opisthobranchia). Am Malacol Bull 18: 49-53.

Watanabe S, Hara M, Watanabe Y. 2000. Male internal fertilization and introsperm-like sperm of the seaweed pipefish (Syngnathus schlegeli). Zool Sci 17: 759-767.

West-Eberhard MJ. 2003. Developmental plasticity and evolution. Oxford University Press, Oxford.

Wilson CJ, Tomkins JL. 2014. Countering counteradaptations: Males hijack control of female kicking behavior. Behav Ecol 25: 470-476.

Wilson N, Tufton TJ, Eady PE. 1999. The effect of single, double, and triple matings on the lifetime fecundity of Callosobruchus analis and Callosobruchus maculatus (Coleoptera: Bruchidae). J Insect Behav 12: 295-306.

Yassin A, Orgogozo V. 2013. Coevolution between male and female genitalia in the Drosophila melanogaster species subgroup. PLoS ONE 8: e57158.

Yip A, Ng SK, Wong WC, Li MK, Lam KH. 1989. Injury to the prepuce. Br J Urol 63: 535-538.

Zaher H. 1999. Hemipenial morphology of the South American xenodontine snakes: With a proposal for a monophyletic Xenodontinae and a reappraisal of colubroid hemipenes. Bull Am Mus Nat Hist 240: 1-168.

Zhong W, McClure CD, Evans CR, Mlynski DT, Immonen E, Ritchie MG, Priest NK. 2014. Immune anticipation of mating in Drosophila: Turandot M promotes immunity against sexually transmitted fungal infections. Proc R Soc B 280: 20132018. 


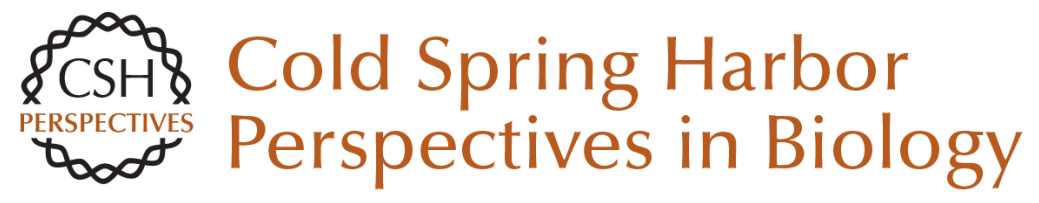

\section{Copulatory Wounding and Traumatic Insemination}

Klaus Reinhardt, Nils Anthes and Rolanda Lange

Cold Spring Harb Perspect Biol 2015; doi: 10.1101/cshperspect.a017582 originally published online April 15, 2015

\section{Subject Collection The Genetics and Biology of Sexual Conflict}

Mechanisms and Evidence of Genital Coevolution: The Roles of Natural Selection, Mate Choice, and Sexual Conflict

Patricia L.R. Brennan and Richard O. Prum

The Evolution of Sexually Antagonistic Phenotypes

Jennifer C. Perry and Locke Rowe

Reproductive Parasitism: Maternally Inherited

Symbionts in a Biparental World

Gregory D.D. Hurst and Crystal L. Frost

Sex-Biased Gene Expression and Sexual Conflict throughout Development

Fiona C. Ingleby, Ilona Flis and Edward H. Morrow

Human Homosexuality: A Paradigmatic Arena for

Sexually Antagonistic Selection?

Andrea Camperio Ciani, Umberto Battaglia and Giovanni Zanzotto

Sexual Conflict Arising from Extrapair Matings in Birds

Alexis S. Chaine, Robert Montgomerie and Bruce E. Lyon

Sexual Conflict and Seminal Fluid Proteins: A

Dynamic Landscape of Sexual Interactions

Laura K. Sirot, Alex Wong, Tracey Chapman, et al.

Conflict on the Sex Chromosomes: Cause, Effect, and Complexity

Judith E. Mank, David J. Hosken and Nina Wedell
Infanticide as Sexual Conflict: Coevolution of

Male Strategies and Female Counterstrategies Ryne A. Palombit

Copulatory Wounding and Traumatic Insemination

Klaus Reinhardt, Nils Anthes and Rolanda Lange

Sexual Conflict in Hermaphrodites

Lukas Schärer, Tim Janicke and Steven A. Ramm

Sexual Conflict and Sperm Competition

Dominic A. Edward, Paula Stockley and David J. Hosken

Sexually Antagonistic Zygotic Drive: A New Form of Genetic Conflict between the Sex

Chromosomes Urban Friberg and William R. Rice

Sex Chromosome Drive

Quentin Helleu, Pierre R. Gérard and Catherine Montchamp-Moreau

Is Sexual Conflict an "Engine of Speciation"? Sergey Gavrilets

Sexual Cannibalism as a Manifestation of Sexual Conflict

Jutta M. Schneider

For additional articles in this collection, see http://cshperspectives.cshlp.org/cgi/collection/

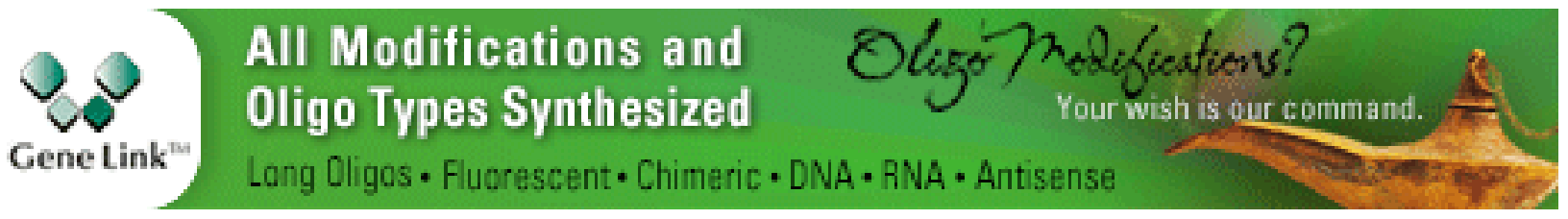


For additional articles in this collection, see http://cshperspectives.cshlp.org/cgi/collection/

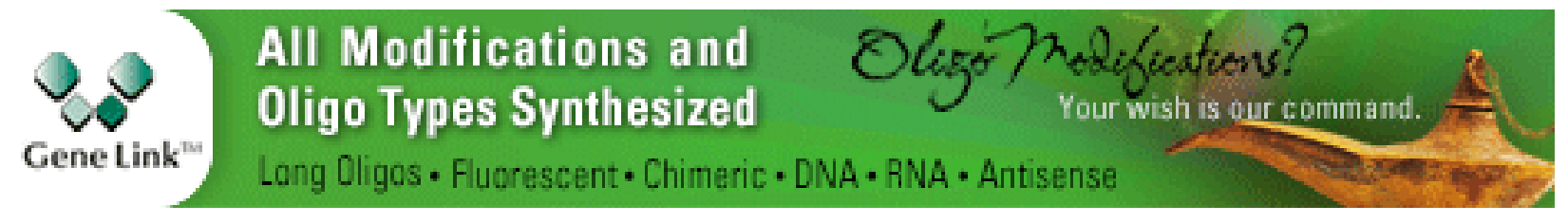

Copyright @ 2015 Cold Spring Harbor Laboratory Press; all rights reserved 